\title{
nkx3.2 mutant zebrafish accommodate jaw joint loss through a phenocopy of the head shapes of Paleozoic jawless fish
}

Tetsuto Miyashita ${ }^{1,2}$, Pranidhi Baddam ${ }^{3}$, Joanna Smeeton ${ }^{4}$, A. Phil Oel ${ }^{1,5}$, Natasha Natarajan ${ }^{4}$, Brogan Gordon ${ }^{1}$, A. Richard Palmer ${ }^{1}$, J. Gage Crump ${ }^{4}$, Daniel Graf ${ }^{3,6}$, and W. Ted Allison ${ }^{1,6 *}$

${ }^{1}$ Department of Biological Sciences, University of Alberta, Edmonton, Alberta, Canada T6G 2E9

${ }^{2}$ Department of Organismal Biology and Anatomy, University of Chicago, Chicago, IL 60637, USA

${ }^{3}$ Department of Dentistry, University of Alberta, Edmonton, Alberta, Canada T6G 2R3

${ }^{4}$ Department of Stem Cell Biology and Regenerative Medicine, W.M. Keck School of Medicine, University of Southern California, Los Angeles, CA 90033, USA

${ }^{5}$ Current Address: Developmental Biology Unit, European Molecular Biology Laboratory, Heidelberg, 69117, Germany

${ }^{6}$ Department of Medical Genetics, University of Alberta, Edmonton, Alberta, Canada T6G 2R7

* Corresponding author. ted.allison@ualberta.ca; 780-492-4430.

KEY WORDS: Skeletal remodeling, Developmental plasticity, Jaw, Joint, Zebrafish, Agnatha, Nkx3.2, Bapx

RUNNING TITLE: Functionally jawless zebrafish 


\section{ABSTRACT}

3 The vertebrate jaw is a versatile feeding apparatus that facilitated explosive diversification. To

4 function, it requires a joint between the upper and lower jaws, so jaw joint defects — such as

5

6

7

8 osteoarthritis or even ankylosis - are often highly disruptive and difficult to study. To describe consequences of jaw-joint dysfunction, we engineered two independent null alleles of a single jaw-joint marker gene, $n k x 3.2$, in zebrafish. These mutations caused zebrafish to become functionally jawless via fusion of the upper and lower jaw cartilages (ankylosis). Despite lacking jaw joints, $n k \times 3.2$ mutants survive to adulthood and accommodate this defect by: a) remodeling their skulls; and b) altering their behavior from suction feeding to ram feeding. As a result of remodeling, $n k x 3.2$ mutants developed superficial similarities to the skull shapes observed in two lineages of ancient jawless vertebrates (anaspids and furcacaudiid thelodonts), including: a fixed open gape, reduced snout, and enlarged branchial region. However, no homology exists in individual skull elements between these taxa, and most of the modified elements in the mutant zebrafish occur outside known expression domains of $n k x 3.2$. Therefore, we interpret the adult $n k x 3.2$ phenotype not as a reversal to an ancestral state, but as convergence due to similar functional requirement of feeding without moveable jaws. This remarkable convergence strongly suggests that jaw movements themselves dramatically influence the development of jawed vertebrate skulls, which implies that functionally viable skull morphologies are finite, with or without functional jaws. Because $n k x 3.2$ null zebrafish display prominent joint ankylosis, drastically modified skull shape, and altered feeding behaviors, these mutants provide a unique model with which to investigate mechanisms of skeletal remodeling and joint diseases.

\section{INTRODUCTION}

The jaw is a functionally versatile innovation that facilitated explosive diversification of gnathostomes (a clade containing jawed vertebrates), but its basic structure is surprisingly simple and highly conserved (Miyashita, 2016). A jaw consists of 'a hinge and caps': upper and lower skeletal levers hinged at a jaw joint (Depew and Simpson, 2006). As the joint enables biting motions, its origin is considered the final step in the evolutionary assembly of the vertebrate jaw (Cerny et al., 2010; Kuratani, 2012; Miyashita, 2016). Across jawed vertebrates, the presumptive jaw joint is marked by the expression of $n k x 3.2$, an NK2 class homeobox gene (a.k.a. bapx), at the midheight of the embryonic mandibular arch (Gillis et al., 2013; Lukas and Olsson, 2018a; Miller et al., 2003; Tucker et al., 2004). Chondrogenesis dorsal to this expression domain gives rise to a palatoquadrate (upper jaw), whereas chondrogenesis ventral to it forms Meckel's cartilage (lower jaw) (Medeiros and Crump, 2012). This basic pattern remains conserved among jawed vertebrates, but later development varies. Marginal 


\section{Miyashita et al. - Functionally jawless zebrafish 3}

bones arise intramembranously around the often endo-/peri-chondrally ossified jaw cartilages except in chondrichthyans (sharks, rays, and skates) (Hall, 2015). In mammals, the jaw joint instead forms between two such intramembranous bones (temporal and dentary), whereas the proximal jaw joint becomes the malleus-incus interface that is, in mice, no longer affected by $N k x 3.2$ knockout (Tucker et al., 2004). Despite these variations after pharyngeal chondrogenesis, no gnathostome lineage secondarily lost functional jaws.

By studying functional jaw loss in our new mutant zebrafish, we asked whether - and how jaw functions affect vertebrate skull shape during development. Clinically documented agnathia in humans typically accompanies severe congenital disorders such as holoprosencephaly and otocephaly, but jaw loss is clearly a secondary effect and not a cause in these cases (Bixler et al., 1985; Brown and Marsh, 1990; Gekas et al., 2010; Schiffer et al., 2002). Instances of temporomandibular joint ankylosis (stiffening due to bone fusion) may result from trauma or infection, or may be congenital (Adekeye, 1983; Chidzonga, 1999; Manganello-Souza and Mariani, 2003). If untreated, the ankylosis can lead to the 'bird face' deformity (El-Sheikh et al., 1996). However, these cases do not fully document the effects of functional jaw loss. In mammalian models, various jaw/skull deformations have been induced by surgical resection, detachment, or repositioning of the jaw muscles and/or bones (Bayram et al., 2010; Gomes et al., 2012; Horowitz and Shapiro, 1955; Lifshitz, 1976; Miyazaki et al., 2016; Rodrigues et al., 2009; Sarnat, 1970; Sarnat and Muchnic, 1971; Toledo et al., 2014). These manipulations occurred well after formation of the jaw skeleton and muscles, and the jaws remained partially functional because of unilateral operations or non-comprehensive disruption. The defects and deformities reported in these studies imply: a) jaw movements are potentially an important factor in shaping the skulls; and b) any allele disrupting jaw movements would be generally maladaptive. Nevertheless, these implications are difficult to explore without an accessible experimental model. To fill this gap, we engineered two distinct null alleles of $n k x 3.2$ in zebrafish. Previously, transient knockdown of $n k x 3.2$ during early development (using morpholinos) had shown fusion of the nascent jaw cartilages in both zebrafish and frogs (Lukas and Olsson, 2018a; Miller et al., 2003). We confirmed in zebrafish that the mutants reproduce this phenotype. Surprisingly, mutant zebrafish are viable — despite loss of the jaw joint — and grow through to adulthood. Functionally jawless as a result, $n k x 3.2^{-/-}$zebrafish dramatically alter skull shape late in ontogeny to facilitate feeding, with the mouth fixed open, the snout reduced, and the branchial region expanded. This open-mouth phenotype, previously unknown in zebrafish or any other jawed vertebrates, also occurred in two extinct lineages of 400-million-plus year-old jawless vertebrates, anaspids and thelodonts. Even though they share no homology in individual facial bones, $n k x 3.2^{-/}$fish accommodate loss of a functional jaw by converging 


\section{Miyashita et al. - Functionally jawless zebrafish 4}

onto these ancient, distantly related agnathan head shapes. Thus, $n k x 3.2$ mutant zebrafish provide a unique model for both skeletal remodeling and joint diseases such as osteoarthritis, and to reevaluate evolutionary implications of phenocopies in general.

\section{MATERIALS AND METHODS}

\section{Animal Ethics}

Zebrafish maintenance and experiments were approved as protocol number AUP00000077 by the Animal Care and Use Committee: Biosciences at the University of Alberta as dictated by the Canadian Council on Animal Care. Other zebrafish work was approved by the University of Southern California Institutional Animal Care and Use Committee.

\section{Animal husbandry}

Embryos were incubated at $28{ }^{\circ} \mathrm{C}$, and treated with 0.003\% PTU (1-phenyl-2-thiourea) in 10\% Hank's saline starting at $24 \mathrm{hpf}$. Larvae were introduced to the nursery at 1 week to $10 \mathrm{dpf}$. Genomic DNA was extracted from clipped fins of 3-5 dpf larvae or from adults. Preserved tissues, embryos, larvae, and adults were all fixed in 4\% PFA, and stored in $100 \% \mathrm{EtOH}$ or $\mathrm{MeOH}$ at $-20{ }^{\circ} \mathrm{C}$ except for adults (preserved in $70 \% \mathrm{EtOH}$ at $4^{\circ} \mathrm{C}$ ).

\section{Molecular genetics}

Nkx3.2 protein is a transcription factor with a homeobox DNA binding domain that is $100 \%$ conserved in amino acid sequence among zebrafish, mouse, and human homologs. In zebrafish, a single $n k x 3.2$ gene is apparent in the genome, and its homology to mammalian $N K X 3.2$ is strongly supported by gene synteny: e.g. the neighbor genes flanking $n k x 3.2$ on zebrafish Chromosome 14 ( $w d r 1$ and bod1l1) are positioned coordinately in mouse, human and spotted gar.

Two disparate regions of the gene were targeted by CRISPR guide RNA (gRNA) or TALENs, producing two disparate null alleles that produced similar phenotypes (Fig. 1A). One allele (ua5011) was engineered with CRISPR/Cas9 (Gagnon et al., 2014) targeted at the beginning of the homeodomain, and it harbors a 20 bp deletion resulting in a frameshift (Fig. 1A; Data Supplement 1). The disrupted translation of codons is predicted to abrogate production of the critical homeobox domain, and instead produce random amino acids. This is predicted to produce a non-functional Nkx3.2 and a null allele. A disparate allele (el802) was generated using TALENs (Barske et al., 2016) targeted at the start of the gene. This produced a stably inherited gene with $20 \mathrm{bp}$ deletion, removing 


\section{Miyashita et al. - Functionally jawless zebrafish 5}

101 the translation start codon (Fig. 1A). The allele $n k \times 3.2^{\text {el802 }}$ is predicted to not produce Nkx3.2 protein.

102 Morphologically, these two alleles are not readily distinguishable from each other (see Results).

\section{CRISPR}

105 To generate $n k x 3.2^{\text {ua5011 }}$, we designed sgRNA to five different targets near or within the $n k x 3.2$

106 homeodomain, which were all injected:

GGCGGCCATCTGACGTCGCT

These targets were selected using the web resource CHOPCHOP (Labun et al., 2016; Montague et al., 2014). Following the protocol developed by Gagnon and colleagues (2014), two different oligonucleotides were ordered: one containing a target sequence led by the SP6 promoter (ATTTAGGTGACACTATA) and followed by the overlapping region

(GTTTTAGAGCTAGAAATAGCAAG) of the reverse oligonucleotide; and the reverse containing the constant, Cas9-binding domain of sgRNA. These oliogonucleotides were annealed after 5-minute incubation at $95^{\circ} \mathrm{C}$, through graded cooling $\left(-2^{\circ} \mathrm{C} \mathrm{s}^{-1}\right.$ to $85^{\circ} \mathrm{C} ;-0.1^{\circ} \mathrm{C} \mathrm{s}^{-1}$ to $\left.25^{\circ} \mathrm{C}\right)$, and filled in for the non-overlapping regions using T4 DNA polymerase (NEB: M0203S). To synthesize sgRNAs using these templates, MegaScriptTM SP6 Transcription Kit (Ambion: AM1330) was used. The RNAs were precipitated in ammonium acetate solution, suspended in UltraPure ${ }^{\mathrm{TM}} \mathrm{H}_{2} \mathrm{O}$, and stored in 2-3 $\mu \mathrm{l}$ aliquots at $-80{ }^{\circ} \mathrm{C}$. For injection, $\operatorname{sgRNA}(\mathrm{s})$ were diluted to $400-600 \mathrm{ng} \mu^{-1}$, with $1 \mu \mathrm{l}$ mixed with $1 \mu \mathrm{l}$ aliquot of Cas9 nuclease from Streptococcus pyogenes (NEB: \#M0646) at $1 \mu \mathrm{g} \mathrm{ml}^{-1}$. This solution was mixed with $3 \mu \mathrm{l}$ of $0.2 \mathrm{M} \mathrm{KCl}, 0.2 \%$ phenol red, and $\mathrm{ddH}_{2} \mathrm{O}$. The final injection volume per embryo was approximately $5 \mathrm{nl}$, with 400-600 pg sgRNA and $1 \mathrm{ng}$ Cas9 nuclease. For control, GFP 5'GA was used at the stage $\mathrm{P}_{0}$ when ubi:switch/RH+AB was crossed, which can be phenotyped by reduction of ubiquitous GFP in the progenies with dsRed expression in heart.

We generated $n k x 3.2^{\text {ua5011 }}$ against $\mathrm{AB}$ background. Cas 9 and sgRNAs targeted for $n k x 3.2$ were coinjected with sgRNA that disrupts GFP GA5' (CTCGGGCTGAAGCTCGGCG), at stages between fertilization and first cleavage, to fertilized eggs collected from the crossing of ua3140 ubi:switch/AB+RH and the background $\mathrm{AB}$ line. At $3 \mathrm{dpf}$, injected larvae were sorted for reduced expression of ubiquitous GFP and the presence of dsRed fluorescence in heart. These larvae provided the $\mathrm{P}_{0}$ population. Sequencing of genomic DNA extracted from fin clips of the $\mathrm{P}_{0}$ adults identified a 


\section{Miyashita et al. - Functionally jawless zebrafish 6}

134 female with a $20 \mathrm{bp}$ deletion to the homeodomain-coding region of $n k x 3.2$ (ua5011). The $\mathrm{P}_{0}$ female

135 carrying this mutation was crossed to the sox 10:GFP transgenic line, and progenies were sorted at $3 \mathrm{dpf}$

136 for the presence of sox 10:GFP expression and the absence of the two markers (ubiquitous GFP

137 expression and red fluorescent heart). ua5011 heterozygotes were identified by both sequencing of

138 extracted gDNA and Restriction Fragment Length Polymorphism (RFLP) analysis using one XmaI

139 (NEB: R01805) restriction site within the deleted region (primers for genotyping: 5'-

140 GGACGAGACGGATCAGGAATC-3'; 5'-CACTCGGCGTGTTCGGTAAA-3'). These F 1

141 heterozygotes were incrossed for $\mathrm{F}_{2}$ embryos, which were genotyped by RFLP analysis and phenotyped

142 at 4 dpf by identifying sox 10:GFP-positive chondrocytes and staining cartilages using alcian blue.

143 Homozygotes were reared with a strictly small-grained diet to the adult stage. In this study,

$144 n k x 3.2^{\text {ua5011/ua5011 }}$ represent $\mathrm{F}_{2}$ generation derived from the $\mathrm{P}_{0}$ mutant female and a wildtype male $(\mathrm{AB}$;

145 sox 10:GFP), whereas comparative wildtype (AB; sox 10:GFP) come from incrossing of half-siblings of

146 the $\mathrm{P}_{0}$ male.

147

\section{Tissue preparation and histology}

149 One- and two-month-old $n k x 3.2^{+/+}$and $n k x 3.2^{-/-}$zebrafish were fixed in 4\% paraformaldehyde for

$15024 \mathrm{hrs}$. Zebrafish were eviscerated prior to decalcification with $0.5 \mathrm{M}$ ethylenediaminetetraacetic acid

151 (EDTA) solution for 4 weeks. Samples were dehydrated post decalcification in a series of graded

152 ethanol and embedded in paraffin. Tissue blocks were embedded in a sagittal orientation and sections

153 were cut at $7 \mu \mathrm{m}$ using a 820 Spencer microtome. Hematoxylin and eosin staining was performed on

154 zebrafish sections by firstly placing sections in an oven at $60{ }^{\circ} \mathrm{C}$ for $10 \mathrm{~min}$. The deparaffinized

155 sections were rehydrated using xylene and graded ethanol (100\%, 95\%, 70\%), followed by staining

with hematoxylin and eosin. The slides were then dehydrated and mounted using Permount.

\section{Skeletal preparation}

159 Alcian blue staining of cartilages partly followed the protocol provided by Michael Shapiro (University

160 of Utah). Specimens fixed in 4\% PFA were rinsed with $\mathrm{ddH}_{2} \mathrm{O}$ and transferred to $70 \%$ EtOH. Once

161 equilibrated, larvae were immersed in alcian blue solution $(0.167 \mathrm{mg} / \mathrm{ml}$ alcian blue; $15 \%$ acetic acid;

$16270 \% \mathrm{EtOH})$, rinsed through $\mathrm{EtOH} / \mathrm{ddH}_{2} \mathrm{O}$ series, and washed in a saturated sodium borate solution.

163 Specimens were immersed in trypsin solution ( $0.125 \%$ trypsin; 30\% sodium borate) overnight, washed

164 in $1 \% \mathrm{KOH}$ solution, bleached in $0.15 \% \mathrm{H}_{2} \mathrm{O}_{2} 0.1 \% \mathrm{KOH}, 25 \%$ glycerol solution, immersed through a

$1651 \% \mathrm{KOH} /$ glycerol graded series into $100 \%$ glycerol for storage. Specimens older than $21 \mathrm{dpf}$ were 


\section{Miyashita et al. - Functionally jawless zebrafish 7}

immersed in $0.005 \%$ alizarin red solution in $1 \% \mathrm{KOH}$ overnight, after the first $1 \% \mathrm{KOH}$ wash and before bleaching in $0.15 \% \mathrm{H}_{2} \mathrm{O}_{2} 0.1 \% \mathrm{KOH}$.

\section{Filming}

Wildtype (AB; sox 10:GFP) and $n k x 3.2^{\text {ua5011/ua5011 }}$ were filmed at 2 months post fertilization to record feeding behavior (Movie S1). A fish was placed in a 1.4L tank with dark background and given brine shrimp larvae. Feeding was filmed using Canon EOS 760D at 30 frames s$^{-1}$ in dimensions $1280 \times 720$ pixels. The films were cropped and assembled using iMovie (ver. 10.1.9, (C) 2001-2018 Apple Inc.) and slowed to $1 / 10$ original speed.

\section{Imaging}

Micro-computed tomography $(\mu C T)$. Two-month-old zebrafish were scanned using MILabs $\mu \mathrm{CT}$ scanner. Scans were reconstructed at a voxel size of $25 \mu \mathrm{m}$. Images were analyzed using AVIZO 3dimensional software (Milabs, Utrecht, Netherlands). 2-Dimensional images used for linear and geometric morphometrics were obtained from AVIZO.

Microscopy. Fluorescent images were acquired on a Zeiss Axio Observer.Z1 with LSM 700 confocal microscope via ZEN 2010 software (version 6.0, Carl Zeiss MicroImaging, Oberkochen). Brightfield imaging of stained preps was performed on a Leica MZ16F dissection microscope (Concord ON, Canada) with 12.8 megapixel digital camera (DP72, Olympus; Richmond Hill ON, Canada).

\section{Morphometrics}

Rationales for morphometric comparison. The purpose of our quantitative comparison is to test phenotypic similarities and differences qualitatively identified in $n k x 3.2^{-/-}$mutants with respect to wildtype zebrafish and anaspids (and thelodonts for gape angles). On the one hand, the skulls of $n k x 3.2^{-}$ /- mutants clearly depart from wildtype morphologically at adult stage (Fig. 2). To describe this morphological departure in greater details, we will present comparison of skeletal growth between $n k x 3.2^{-/-}$and wildtype elsewhere. On the other hand, it is difficult to assess observed similarities between $n k x 3.2^{-/-}$phenotype and the general head configuration in anaspids. Zebrafish and anaspids are distant to each other phylogenetically: the former is nested deep within, in the ascending order, cypriniforms, teleosts, neopterygians, actinopterygians, osteichthyans, and gnathostomes, whereas anaspids represent either a stem gnathostome or even a stem cyclostome lineage (Donoghue et al., 2000; Janvier, 2007, 1996; Keating and Donoghue, 2016; Miyashita et al., 2019). The dermatocranium 
of a zebrafish is macromeric, although that of an anaspid is largely micromeric with scales of acellular bone (Blom et al., 2001). There is no morphological correspondence in individual elements of the skull roof between zebrafish and anaspids. The parabranchial cavity is closed by the operculum in zebrafish, whereas each branchial pouch had its own outlet in the series of external pores in anaspids (Blom et al., 2001). A single gene mutation in $n k x 3.2$ did not reverse these, and other morphological differences accumulated after the last common ancestor of zebrafish and anaspids. For morphometric comparison, we chose metric traits that can be identified in both zebrafish and anaspids.

Linear morphometrics. The fixed open gape is similar between $n k x 3.2^{-/-}$mutants and anaspids. We compared this trait by taking the angle between supporting skeletal elements of the upper and lower lips in both taxa. In zebrafish, the angle was taken by extrapolating the axis of the premaxilla until it meets the axis of the dentary. At stages younger than the onset of dermal ossification (4 and $14 \mathrm{dpfs}$ ), the angle was measured between the axes of the palatal process (palatoquadrate) and Meckel's cartilage. In anaspids, the upper and lower lips are demarcated by a series of plates or relatively larger scales, which allowed delineation of the gape angle (measured at where the extrapolated upper and lower lip margins meet). The angle was measured similarly in thelodonts, except that the lip margins were identified along the series of small marginal scales. Gape angle exhibits a roughly normal distribution within each of the age class of both $n k x 3.2^{-/-}$and wildtype zebrafish and among anaspids (see Data Supplement 2). In addition to gape angles, we measured lengths of skulls and lower jaws in zebrafish, and orbit diameter in anaspids and thelodonts. Original measurements are available in Data Supplement 2.

In $n k x 3.2^{-/-}$zebrafish, the gape angle increases progressively with age, and thus with increasing body size. Anaspids and thelodonts overall have much greater range of body size than zebrafish. Unlike $n k x 3.2^{-/-}$zebrafish, however, the gape angle appears to vary independently of body size in anaspids. No correlation exists between gape angle and orbit diameter in anaspids, regardless of whether among those specimens falling in the size range of zebrafish or across the entire clade $(r=-0.114 ; P=0.306)$. Although eye size is generally negatively allometric in vertebrates (Howland et al., 2004), the orbit diameter is one reliable, structurally intact metric trait in this clade, because most specimens are not preserved in entire body length, and because other reference measurements (e.g., body height) are affected by taphonomic deformation or simply not preserved in most specimens (Blom et al., 2001; Blom and Märss, 2010; Janvier, 1996; Sansom et al., 2010). In thelodonts, the relationship remains to be tested between body size and gape angles because of small sample size $(n=5)$. 


\section{Miyashita et al. - Functionally jawless zebrafish 9}

232 Geometric morphometics. Eight landmarks were assigned to both zebrafish (2 mpf) and anaspid 233 samples for geometric morphometric comparison. These landmarks capture general configuration of 234 the heads (1: anterior tip of upper lip; 2: junction between upper and lower lips; 3: anterior tip of lower 235 lip; 4: nostril, or nasohypophyseal opening; 5: anterior extremity of orbit; 6: posterior extremity of 236 orbit; 7: trunk-head boundary at dorsal outline; 8: ventral point of hypobranchial region). These 237 landmarks describe structures homologous across vertebrates (landmarks 4, 5, 6) or geometrically 238 determined positions comparable across vertebrates. They are free of morphological discontinuity 239 between anaspids and gnathostomes (none of the landmarks represents anaspid- or gnathostome240 specific morphology). TpsDig (Rohlf, 2018) was used to place landmarks on two-dimensional images 241 of anaspid and zebrafish. The digitized file was entered into MorphoJ software (Klingenberg, 2011) 242 and all images were aligned using the anterior and posterior extremity of the orbits. These landmark 243 data were transformed using the procrustes superimposition method (Rohlf, 1999), and the resulting 244 coordinates were compared using Principal Component Analysis (PCA). In PCA, PC scores from anapsid, $n k x 3.2^{+/+}$and $n k x 3.2^{-/-}$zebrafish were grouped by equal frequency ellipses with a $\mathrm{P}$ value of 0.95 .

Rationales for selection of comparative taxa in geometric morphometrics. From the pool of nearly a thousand catalogued specimens of anaspids, we selected a total of 70 specimens that show lateral compression during the fossilization process, with the least taphonomic artifact, to reflect lateral view of the heads. Furcacaudiid thelodonts were excluded from geometric morphometrics because only a handful of exceptionally preserved specimens are available. The sample size is small for this latter group $(n<5)$, and all such specimens were collected from a single locality, making it difficult to identify (and thus control for) taphonomic artifacts. In addition, landmarks cannot be assigned confidently in this group. The nasohypophyseal opening cannot be located precisely because of the micromeric nature of the integument on the dorsal side of the head (Wilson and Caldwell, 1998, 1993). The transition from head to trunk is ambiguous along the dorsal outline because there is no apparent change in morphology of the scales (Wilson and Caldwell, 1998, 1993).

There are many other lineages of jawless vertebrates, including living cyclostomes, heterostracans, thelodonts, galeaspids, pituriaspids, and osteostracans, in the order of nested hierarchy toward the crown-group gnathostomes (Janvier, 2007, 1996). Living cyclostomes are difficult to compare as they have an anguilliform profile and lack ossified skeletons, or cartilages unambiguously 
Miyashita et al. - Functionally jawless zebrafish 10

264 2019). Extinct jawless vertebrates generally have a depressiform profile (Janvier, 1996). Therefore,

265 direct shape comparison is difficult with the compressiform zebrafish and anaspids.

266 Among non-depressiform jawless stem gnathostomes, the lips are typically preserved poorly.

267 Furcacaudiid thelodonts have a lateromedially compressed body profile, and have the lip morphology

268 consistent with that of anaspids (Wilson and Caldwell, 1998, 1993). These similarities suggest that

269 depressed lower lips are a general condition along the gnathostome stem, as reconstructed

270 conventionally across the stem group.

271

272

\section{RESULTS}

273

274

Jaw joint is ankylosed in $n k x 3.2$ null alleles

275

At 4 days post fertilization (dpf), $n k x 3.2^{-/-}$zebrafish replicated the $n k x 3.2$ morpholino knockdown

phenotype: the absence of a jaw joint (Miller et al., 2003). The palatoquadrate and Meckel's cartilage

fused together, and the retroarticular process was absent (Fig. 1D, G, I). Apart from joint ankylosis, no

marked differences were apparent in overall morphology or survival rates between $n k x 3.2^{-/-}$mutants and wildtype (some minor difference in skull size and lower jaw proportions are discussed in the next section). Heterozygotes were morphologically indistinguishable from wildtype (Fig. 1C, F), and the $n k x 3.2$ alleles displayed recessive Mendelian inheritance $\left(\mathrm{F}_{2}\right.$ genotypes followed Mendelian ratio; heterozygotes developed wildtype morphology). Remarkably, these functionally jawless homozygous mutants survived beyond early larval stages.

\section{Functionally jawless $n k x 3.2^{-/-}$zebrafish modify skull shapes late in ontogeny}

Contrary to the maladaptive nature of jaw dysfunctions in general, $n k x 3.2^{-/-}$zebrafish continued to grow without a jaw joint. Marked phenotypic differences against wildtype began to emerge between the $2^{\text {nd }}$ and $3^{\text {rd }}$ weeks post fertilization (Fig. 2). The lower jaw became downturned in $n k x 3.2^{-/-}$fish resulting in a rigidly fixed open mouth, whereas both upper and lower jaws were upturned in wildtype zebrafish (Fig. 2A, B). This timing coincides with the onset of ossification and the period of active feeding in normal juveniles (Cubbage and Mabee, 1996; Kimmel et al., 1995). Although the palatoquadrate and Meckel's cartilage remained fused in $n k x 3.2^{-/-}$mutants, skeletal staining reveals that the upper and lower jaw elements ossified independently of each other - still without a ball-and-socket joint structure (Fig. 3A, B). All skull elements in $n k x 3.2^{-/-}$mutants ossified without apparent delay. 
Miyashita et al. - Functionally jawless zebrafish 11

perichondrium lies between the ossifying quadrate and articular — so the two bones remained distinct elements - but this interface had none of those essential components of synovial diarthrosis (Fig. 3D, E). Many other osteological differences emerged by this stage. Normally, the premaxilla and the maxilla swing forward to sit nearly vertical and are hinged by the kinethmoid for suction feeding (Hernandez, 2000; Hernandez et al., 2007) (Fig. 2C). In $n k x 3.2^{-/}$mutants, however, the premaxilla and the maxilla became oriented posteroventrally and abutted against the anterior margin of the orbit (Fig. 2D). The kinethmoid was reduced into a fused bony process, unlike a rod-like hinge element in wildtype (Hernandez et al., 2007). The downturned lower jaws of the $n k x 3.2^{-/-}$mutants were relatively shorter than the normal lower jaws of wildtypes. The basihyal protruded anteroventrally as much as the lower jaw, implying that the muscle connecting those two elements ( $\mathrm{m}$. intermandibularis posterior) (Schilling and Kimmel, 1997) may be responsible for the lower jaw orientation. As a result of these modifications, $n k x 3.2^{-/-}$mutants had a shorter snout, a fixed open gape, and a dorsoventrally tall profile. Linear morphometrics corroborated the departure from normal morphology in $n k x 3.2^{-/-}$mutants in the latter half of the first month (14 dpf onward). For absolute size, no significant difference $(P>$ $0.05)$ in skull length emerged between wildtype and $n k x 3.2^{-/-}$mutants except at $4 \mathrm{dpf}(t=2.202 ; P=$ 0.338) (Fig. 4B). Also at this stage, the lower jaws appear to be shorter relative to skull length in the mutants than in the wildtypes ( $t=2.809 ; P=0.0078)$ (Fig. 4C). These minor but statistically significant differences at $4 \mathrm{dpf}$ may be a direct consequence of the ankylosis between palatoquadrate and Meckel's cartilage. By the second week, however, differences between the mutants and wildtypes became nonsignificant in these metric traits. The lower jaw depression (gape angle $>45^{\circ}$ ) in the mutants was pronounced at $21 \mathrm{dpf}(t=-11.834 ; P<<0.01)$ (Fig. 4A), but proportional changes to lower jaw lengths in the same mutants were only expressed in significant magnitude at 1 month ( $21 \mathrm{dpf}: t=1.7225 ; P=$ $0.091559 ; 30$ dpf: $t=10.56 ; P<<0.01$ ) (Fig. 4C). This lag between the two traits indicates that the rate of skeletal growth in the jaws followed changes in their orientation for a greater gape (and thus resulting in functional shift). Morphological variations within a cohort of $n k x 3.2^{-/-}$mutants were greater at this stage than in any other, as indicated by the range of variation in orientations and relative lengths of the lower jaws (Fig. 4A, C).

\section{The adult $n k x 3.2^{-/-}$phenotype accommodates functional jaw loss}

At 2 months of age and approaching sexual maturity nearly all $n k x 3.2^{-/-}$mutants had a gape angle greater than 90 degrees (Fig. 4A). These $n k x 3.2^{-/ 2}$ adults continued to be characterized by the morphological differences identified at $1 \mathrm{mpf}$. The nostrils sat between the eyes because the snout was reduced in length relative to wildtype zebrafish. The skulls appeared to be more highly ossified in 


\section{Miyashita et al. - Functionally jawless zebrafish 12}

$n k x 3.2^{-/-}$mutants than in wildtype, where massive bones and cartilages were identified around the interface of quadrate and articular, in the lower branchial region, and in the laterally expanded operculum (Figs. 2J, G, M, N, 5B; Movie S1). All homozygous mutants showed the descriptive skeletal traits identified here. Morphologically, the phenotypic effects of the two alleles $\left(n k x 3.2^{\text {ua5011 }}\right.$ and $n k x 3.2^{\text {el802}}$ ) were virtually indistinguishable from each other at respective ages (Fig. $2 \mathrm{G}$, J), given variations within a strain (for examples, see variation in gape angles, relative lengths of lower jaws, or sexual dimorphism in $n k x 3.2^{\text {ua5011 }}$ : Figs.2M, N, 4A, C).

With their modified skulls, adult $n k \times 3.2^{-/-}$mutants exhibited feeding behaviors markedly different from wildtype (Fig. 5; Movie S1). Wildtype zebrafish feed by suction using rapid lower jaw depression and a forward swing of the mobile premaxilla-maxilla complex shortly followed by opening of the operculum (Fig. 5A), consistent with general teleost feeding mechanics (Alexander, 1970, 1969; Lauder, 1980, 1979; Westneat, 2005, 2004). In contrast, adult $n k x 3.2^{-/-}$mutants were constrained by the fixed upper jaw unit and open gape. They instead showed ram feeding behaviors (swimming through food) (Fig. 5B). The jaws remained fixed, and no significant dorsoventral movement was observed. Whereas in wildtype one complete cycle of the jaw opening and closing took approximately 80 milliseconds (and approximately a tenth of a second to the closure of the operculum), $n k x 3.2^{-/-}$mutants required double that time from changing direction of swimming toward food $(0 \mathrm{~s})$ to doing so again away from the food $(0.2 \mathrm{~s})$ in this particular feeding episode in Fig. 5B. A detailed analysis of the feeding mechanics is beyond the scope of this paper and is currently the focus of our study, with filming at higher speed and resolution.

This ram-feeding behavior was correlated with skull remodeling in $n k x 3.2^{-/-}$mutants. In zebrafish skulls, the bones form endochondrally (quadrate, anguloarticular, basihyal) or intramembranously (premaxilla, maxilla, dentary, jugal, opercular, preopercular) (Cubbage and Mabee, 1996; Schilling and Kimmel, 1997). Much of the skeletal remodeling observed in adult $n k x 3.2^{-/-}$ mutants occurred in the intramembranous bones - spatially and temporarily well outside the known expression domain of $n k x 3.2$ (Askary et al., 2017; Miller et al., 2003). Until past 1 mpf, the fusion between jaw cartilages was not completely ossified in these mutants, potentially allowing plastic remodeling (Fig. 2e, 1). These observations suggest that $n k x 3.2^{-/-}$zebrafish accommodate functional jawlessness through remodeling of the skull and changes to feeding behavior.

\section{$n k x 3.2^{-/-}$zebrafish converge onto agnathans in overall head shapes}

Through this dramatic remodeling of the skull, $n k x 3.2^{-/-}$zebrafish assumed a head shape reminiscent of two lineages of extinct jawless vertebrates that have laterally compressed body profiles: 1) birkeniiform 
Miyashita et al. - Functionally jawless zebrafish 13

363 anaspids (Fig. 6C), stem cyclostomes known mostly from the Silurian period (Blom et al., 2001;

364 Miyashita et al., 2019); and 2) furcacaudiid thelodonts (Fig. 6D), much more elusive stem

365 gnathostomes known from the Silurian and Devonian periods (Märss et al., 2007; Wilson and Caldwell, 1998). Qualitatively, the resemblance is particularly striking in overall head shape characters, including: fixed gape (depressed lower lips), shortened snout, interorbital position of nostril, proportionally large branchial region, and massive parietal region behind the occiput.

In linear morphometrics, the gape angle between upper and lower lips reveals that $n k x 3.2^{-/-}$ mutants closely resembles the anaspid- and thelodont-like conditions late in ontogeny (Fig. 4A). The trait in $n k x 3.2^{-/-}$mutants departed from that in wildtype after the onset of skull ossification and active feeding (14-21 dpf), and overlaps with the range occupied by anaspids and thelodonts in later stages (1 and $2 \mathrm{mpf}$ ). When the jaws were at rest, the gape angle in wildtype zebrafish was consistently around 30 degrees regardless of ontogenetic stages. This was also the case for the $n k x 3.2^{-/-}$mutants at 4 and 14 dpf when they still rely on yolk as main or partial intake. The gape angle increased steadily thereafter in the mutants.

In landmark-based geometric morphometrics, $n k x 3.2^{-/-}$mutants aligned more closely with anaspids than wildtype along the principal components (PCs) that explain the adult phenotype (PCs 1 and 5) (Fig. 6E, F). Nearly one third of the overall shape variation loaded on PC1 and primarily concerned anteroposterior length and dorsoventral height of the entire head. Compared to wildtype zebrafish, $n k x 3.2^{-/-}$mutants and most anaspids had a much shorter snout (with the lips and the nostrils shifting posteriorly toward the eye) and dorsoventrally deeper lower lips. PC 5 explained $7.0 \%$ of overall shape variation, and the traits that vary along it were orientation of lower lip and relative height of nostrils, which clearly set wildtype zebrafish apart from $n k x 3.2^{-/-}$mutants and anaspids. On the Cartesian grid of PCs 1 and 5, $n k x 3.2^{-/-}$mutants overlapped with anaspids in morphospace occupation and apart from wildtype zebrafish (Fig. 6F). The area of overlap also indicated that $n k x 3.2^{-/-}$mutants are broadly similar to anaspids in these PCs, not just to one or a few individual anaspid taxa. PCs 2-4 (not shown in Fig. 6) largely explain variation among anaspids or within wildtype/mutant zebrafish samples and were therefore uninformative for comparison between the groups (datasets containing landmark coordinates and Procrustes transformation are provided in Data Supplement 3). 
Miyashita et al. - Functionally jawless zebrafish 14

Our $n k x 3.2^{-/-}$zebrafish reinforce the morphant-based insight that this transcription factor is essential to the development of jaw joint in non-mammalian vertebrates (Miller et al., 2003). This is likely the widespread condition among jawed vertebrates. $N k \times 3.2$ knockdown also results in fusion between the palatoquadrate and Meckel's cartilage in amphibians (Lukas and Olsson, 2018a), and a similar phenotype is observed in chicks with ectopic expression of BMP4 and FGF8 that repressed Nkx3.2 (Wilson and Tucker, 2004). In mammals, the palatoquadrate (malleus) and Meckel's cartilage (incus) migrate to form middle ear ossicles. The malleus-incus joint is not affected in $N k x 3.2^{-/-}$mice, even though the malleus becomes narrower in the mutants, and even though $N k \times 3.2$ plays a role in specification of the gonium and the anterior tympanic ring (Tucker et al., 2004). Aside from the head, $N k x 3.2$ plays a role in various structures in mice and chicks, including the axial column (Herbrand et al., 2002; Lettice et al., 2001; Murtaugh et al., 2001) and visceral lateralities of the spleen and pancreas (Hecksher-Sørensen et al., 2004; Schneider et al., 1999). We will test in a forthcoming work whether or not $n k x 3.2^{-/-}$zebrafish have parallel phenotypes to these amniote mutants in the axial skeletons or visceral literalities.

During development of the jaw joint, $n k x 3.2$ is thought to specify the joint interzone by inhibiting maturation or hypertrophy of the chondrocytes (Miller et al., 2003; Smeeton et al., 2016). Similar functions have been ascribed to $\operatorname{irx} 7$ and $\operatorname{irx} 5 a$ in the hyoid joint (Askary et al., 2015). This is consistent with the predicted regulatory function of $N k x 3.2$ in vertebral development, intervertebral and interphalangeal joint formation, or somatic chondrogenesis in general (Herbrand et al., 2002; Lettice et al., 2001; Murtaugh et al., 2001) — via repression of Runx2, by upregulating Col2 $\alpha 1$, and/or through a positive feedback loop with Sox9 (Smeeton et al., 2016). These insights are based on: a) experimental results using amniote embryos or somitic mesodermal cell cultures (Cairns et al., 2008; Kawato et al., 2012; Lengner et al., 2005; Murtaugh et al., 2001; Provot et al., 2006; Yamashita et al., 2009; Zeng et al., 2002); and b) clinical and genetic studies of human pathologies, including osteoarthritis and spondylo-megaepiphyseal-metaphyseal dysplasia (including pseudoepiphyses) (Caron et al., 2015; Hellemans et al., 2009). Before this study, however, no mutants were available to specifically address these potential mechanisms of $n k x 3.2$ functions in the mandibular arch.

\section{The open-mouth phenotype results from plastic remodeling}

The late onset and topology of skull/jaw remodeling suggests that $n k x 3.2^{-/-}$zebrafish accommodate the loss of the jaw joint via a plastic response. Other than the absence of jaw joint, $n k x 3.2^{-/-}$zebrafish appear normal until metamorphosis (14-21 dpf) (Fig. 1D, G). As the skull ossifies, however, the observed phenotype becomes increasingly prominent (Fig. 2B, D, G, J, M, N). Although the fused jaw 
Miyashita et al. - Functionally jawless zebrafish 15

cartilages clearly result from $n k x 3.2$ mutation, $n k x 3.2$ loss-of-function, by itself, seems unlikely to yield all the rest of phenotypic effects described here. A genome-wide analysis suggests that $n k x 3.2$ patterning effects in the skull are restricted to the mid-portion of the mandibular arch (Askary et al., 2017). Nor does $n k x 3.2$ have known expression or function in the intramembranously ossified skull elements (Miller et al., 2003; Tucker et al., 2004), which are dramatically modified in our $n k x 3.2^{-/-}$fish. The hypertrophied mandibular cartilage may result from $n k x 3.2$ loss-of-function in regulating local chondrogenesis (Smeeton et al., 2016). Still, further investigation is warranted because in amphibians an ectopic cartilage formed in the mandibular arch with $N k x 3.2$ overexpression, not repression (Lukas and Olsson, 2018b).

A comparative survey across vertebrates supports our interpretation of the adult $n k x 3.2^{-/-}$ phenotype as skeletal remodeling to accommodate the jaw joint loss. Discrete variation in cichlid jaw morphology has an epigenetic basis in behaviorally mediated skeletal remodeling, where gaping frequencies in juveniles correlate with dimensions of the retroarticular process $(\mathrm{Hu}$ and Albertson, 2017). The magnitude of morphological changes in the adult $n k x 3.2^{-/-}$phenotype also appears consistent with a series of surgical experiments in mammalian jaw skeletons (Bayram et al., 2010; Gomes et al., 2012; Horowitz and Shapiro, 1955; Lifshitz, 1976; Miyazaki et al., 2016; Rodrigues et al., 2009; Sarnat, 1970; Sarnat and Muchnic, 1971; Toledo et al., 2014) or with the 'bird face' deformity observed in clinical cases of the temporomandibular joint ankylosis in humans (El-Sheikh et al., 1996). Collectively, these studies show that latent potentials of development allow a plastic trait to become expressed in jaw skeletons.

Variation resulting from developmental plasticities — whether induced by environmental cues, developmental perturbation, or mutation — are often non-random and adaptive (Palmer, 2012; WestEberhard, 2005a, 2005b, 2003). Such non-random, adaptive responses are documented across wide ranges of taxa and structures, including: more robust claws in crabs fed with harder food items (Smith and Palmer, 1994); longer or shorter appendages of barnacles transplanted between wave-exposed and protected shores (Kaji and Palmer, 2017; Neufeld and Palmer, 2008); and thickened shells of gastropods exposed to predator cues (Appleton and Palmer, 1988; Edgell and Neufeld, 2008). Phylogenetically closer to zebrafish, cichlids have been extensively studied for developmental plasticity in jaw skeletons, such as: the relationship with gape frequencies and retroarticular processes, mentioned above (Hu and Albertson, 2017); antisymmetric development of the jaws in scale-eating specialists (Stewart and Albertson, 2010); and various dietary effects on feeding morphology (Galis, 1993; Greenwood, 1965; Liem and Osse, 1975; Meyer, 1987; Wimberger, 1992, 1991). Ram feeding 
Miyashita et al. - Functionally jawless zebrafish 16

460 facilitated by the fixed open gape in the adult $n k x 3.2^{-/-}$zebrafish corroborates non-random, adaptive 461 accommodation of the jaw joint defect.

\section{Jaw joint functions constrain skull morphology in vertebrates}

464 The drastically remodeled skull of adult $n k x 3.2^{-/-}$zebrafish highlights jaw movements as an important 465 factor in the development — and thus morphological diversity — of jawed vertebrate skulls (Depew et al., 2005; Depew and Compagnucci, 2008; Depew and Simpson, 2006). Functional jaw loss resulting from $n k x 3.2$-null mutations allowed the mutants to depart so markedly in morphology from their wildtype cousins, despite the nearly identical genetic backgrounds. This departure implies that movements at the jaw joint limit skull forms. The specific combination of traits observed in adult $n k x 3.2^{-/-}$zebrafish - e.g., nostrils in interorbital position, premaxilla and maxilla abutted against antorbital wall, kinethmoid reduced, basihyal protrusion — is likely maladaptive and unavailable to zebrafish when the jaws function properly. Simultaneously, the absence of a jaw joint (or jaw apparatus altogether) also limits functionally viable forms. This interpretation is bolstered by the superficial convergence in head shapes between $n k x 3.2^{-/-}$zebrafish and two Paleozoic agnathan lineages (anaspids and furcacaudiform thelodonts). The $n k x 3 \cdot 2^{-/-}$zebrafish and these agnathans share a functional requirement — the absence of a hinge joint between upper and lower lips - and transversely compressed body profile. No evidence suggests any more similarities in the otherwise wildtype-like young mutants (Fig. 1D, G) until the lower jaw skeletons begin rotating posteroventrally post $14 \mathrm{dpf}$ (Fig. 2B, D). Therefore, we interpret the anaspid/thelodont-like traits in the adult $n k x 3.2^{-/-}$zebrafish not as recapitulations of conserved, genetically hard-wired early vertebrate development (atavism), but rather as parallel developmentally plastic responses to shared growth conditions that were experienced by early vertebrates in a zebrafish skull (convergence).

Thus, jaw-joint loss ( $n k x 3.2$ loss-of-function phenotype) released $n k x 3.2^{-/-}$zebrafish from developmental constraints to facilitate jaw movement, and exposed them to a different functional requirement: feeding without mobile jaws. A fixed open gape - accompanied by modification of the skull elements - is one morphological solution to the functional loss of the jaw joint, which is corroborated by ram feeding exhibited by $n k x 3.2^{-/-}$mutants (Fig. 5B; Movie S1). The magnitude of modification documented post-hatching (Figs. 1-5) is a testament to significant functional optimization within the bounds of the gnathostome bauplan. Simultaneously, well-constrained occupancy by the $n k x 3.2^{-/-}$in the PCA plot (Fig. 6F) implies that alternative morphological patterns are either functionally non-viable (e.g., fixed closed gape) or developmentally non-accessible (e.g., ectopic 


\section{Miyashita et al. - Functionally jawless zebrafish 17}

the vertebrate bauplan allows a limited repertoire of functionally viable morphological patterns, onto which forms may converge under a given functional constraint.

In support of our interpretation, remarkable convergences arise via developmental plasticity under similar functional requirements - even in the absence of homology in individual skeletal elements - between taxa widely separated chronologically and phylogenetically. Bichirs (Polypterus) routinely trained under terrestrial conditions modify the pectoral fin skeleton through plasticity and develop morphological conditions observed in stem tetrapods (Standen et al., 2014). In another, vav2 and waslb mutant zebrafish develop limb-like long bones connected by joints within the pectoral fins (Hawkins et al., 2018, preprint). West-Eberhard (2005b) reviewed a goat born with congenital paralysis of forelimbs, which performed bipedal locomotion. This behavioral accommodation led to highly modified musculoskeletal anatomy of the axial column, pelvis, and hindlimbs (Slijper, 1942a, 1942b). As shown in $n k x 3.2^{-/-}$zebrafish, these experimental manipulations and clinical reports illustrate that adaptive forms emerge from developmentally plastic responses to functional constraints — and therefore may converge onto phenotype independently exploited by a distant lineage - even after development has laid out lineage-specific patterns (such as homologies of individual bones).

\section{nkx3.2 mutants as a unique model for skeletal development and disease}

Mechanisms of developmentally plastic remodeling, whether at the level of whole-animal behavior or gene transcription, remain an elusive component of skeletal development that is challenging to test experimentally. Therefore, $n k x 3.2^{-/-}$zebrafish provide a unique experimental system in which to test further the role of a joint in skeletal development. For example: a) What genetic mechanisms regulate the remodeling of intramembranous ossifications? b) What components of the remodeling process respond to jaw-joint dysfunction? and c) Does any feedback exists to coordinate remodeling between developmentally independent, but functionally connected units (e.g., premaxilla-maxilla complex and kinethmoid)? Such insights would begin to fill in knowledge gaps regarding skeletal and joint diseases including osteoarthritis and joint ankylosis.

The non-atavistic nature of the $n k x 3.2^{-/-}$phenotype is potentially useful to reevaluate evolutionarily inspired interpretations of phenocopies in general. There are no evolutionary relationships in the similarities between $n k x 3.2^{-/-}$zebrafish and anaspids or thelodonts. Anaspids are a stem cyclostome lineage (Miyashita et al., 2019) (Fig. 6G), and thus a poor surrogate for an ancestral state. The lineages between anaspids and thelodonts, or those between thelodonts and the gnathostome crown, do not share a similar combination of morphological traits, but instead are dorsoventrally depressed forms (Janvier, 1996; Miyashita, 2016; Miyashita et al., 2019) (Fig. 6G). Finally, head 
Miyashita et al. - Functionally jawless zebrafish 18

similarities between the mutants and the stem taxa do not extend beyond overall configuration. No skull elements are lost or replaced in $n k \times 3.2^{-/-}$zebrafish to achieve the anaspid/thelodont-like micromery (Blom et al., 2001; Janvier, 1996; Märss et al., 2007). Therefore, the adult $n k x 3.2^{-/-}$ phenotype clearly does not represent a reversal to an ancestral state. Although experimental phenocopies are often interpreted as atavistic (ancestral reversal), alternative interpretations are seldom tested (Smith and Schneider, 1998). Here, our $n k x 3.2^{-/}$zebrafish present developmental plasticity as a testable alternative to atavistic reversal to explain a phenocopy. By showing that a gnathostome can survive without a jaw, the anaspid/thelodont-like $n k x 3.2^{-/-}$zebrafish also offer a comparative model to make inferences about the functional morphology of these long-extinct agnathans.

\section{Acknowledgements}

We thank B.F. Eames (University of Saskatchewan) for facilitating our collaboration; M.E. Bronner (California Institute of Technology), S.J. Childs (University of Calgary), M.I. Coates, V.E. Prince, and M.W. Westneat (University of Chicago) for discussion; and members of the Allison and Prince labs for maintenance of $n k x 3.2^{\text {uasol1 }}$.

\section{Competing interests}

The authors declare no competing or financial interests.

\section{Author contributions}

T.M. conceived project; T.M. and A.P.O. performed experiments resulting in $n k x 3.2^{\text {uas011 }}$; J.S. and N.N. performed experiments resulting in $n k x 3.2^{e l 802}$; P.B. and B.G. provided $\mu \mathrm{CT}$ scanning and histological sampling; T.M. and P.B. conducted morphometric analyses; T.M., P.B., A.R.P., J.G.C., D.G., and W.T.A. analyzed data; T.M. wrote the paper with inputs from P.B., A.P.O., J.S., A.R.P., J.G.C., D.G., and W.T.A.

Funding. This work was supported by Natural Science and Engineering Research Council grants RGPIN-2014-04863, RGPIN-2014-06311, and RGPIN-2015-06006 (to A.R.P., D.G., and W.T.A., respectively) and National Institute of Health grants R35DE027550 and K99 DE027218 (to J.G.C. and J.S., respectively).

\section{Supplementary information}


bioRxiv preprint doi: https://doi.org/10.1101/776351; this version posted October 18,2019 . The copyright holder for this preprint (which was not certified by peer review) is the author/funder, who has granted bioRxiv a license to display the preprint in perpetuity. It is made available under aCC-BY-NC 4.0 International license.

Miyashita et al. - Functionally jawless zebrafish 19

558 Sequence information, measurements, and landmark coordinates are available as data supplements to 559 this paper.

561 Movie S1. Feeding behaviour and 3D $\boldsymbol{\mu C T}$ scans of jawless zebrafish. Phenotypic comparison of

$562 n k x 3.2^{-/-}$and wildtype zebrafish. Three-dimensional rendering of $\mu \mathrm{CT}$ scan of the age-matched $n k x 3.2^{-/-}$ 563 (ua5011) and wildtype (AB strain) zebrafish at $2 \mathrm{mpf}$, each followed by filming of feeding behavior on 564 brine shrimp played at $1 / 10$ original speed.

565

566 Data supplements

567 Data supplement 1. Sequence information for the $n k x 3.2$ allele ua5011.

568 Data supplement 2. Gape angles and other linear measurements in zebrafish; gape angles and orbit 569 diameter in anaspids.

570 Data supplement 3. Thin-plate-spline landmark data in zebrafish (wildtype and $n k x 3.2^{-/}$) and anaspids 571 used for Procrustes transformation, which were subjected to principal component analysis. 
Miyashita et al. - Functionally jawless zebrafish 20

574

575

576

577

578

579

580

581

582

583

584

585

586

587

588

589

590

591

592

593

594

595

596

597

598

599

600

601

602

603

604

605

606

\section{REFERENCES}

Adekeye EO. 1983. Ankylosis of the mandible: Analysis of 76 cases. J. Oral Maxillofac. Surg. 41:442449. doi:10.1016/0278-2391(83)90129-5

Alexander RM. 1970. Mechanics of the feeding action of various teleost fishes. J. Zool. 162:145-156. doi:10.1111/j.1469-7998.1970.tb01261.x

Alexander RMcN. 1969. Mechanics of the feeding action of a cyprinid fish. J. Zool. 159:1-15. doi:10.1111/j.1469-7998.1969.tb03067.x

Appleton RD, Palmer AR. 1988. Water-borne stimuli released by predatory crabs and damaged prey induce more predator-resistant shells in a marine gastropod. PNAS 85:4387-4391. doi:10.1073/pnas.85.12.4387

Askary A, Mork L, Paul S, He X, Izuhara AK, Gopalakrishnan S, Ichida JK, McMahon AP, Dabizljevic S, Dale R, Mariani FV, Crump JG. 2015. Iroquois proteins promote skeletal joint formation by maintaining chondrocytes in an immature state. Dev. Cell 35:358-365. doi:10.1016/j.devcel.2015.10.004

Askary A, Xu P, Barske L, Bay M, Bump P, Balczerski B, Bonaguidi MA, Crump JG. 2017. Genomewide analysis of facial skeletal regionalization in zebrafish. Development 144:2994-3005. doi:10.1242/dev.151712

Barske L, Askary A, Zuniga E, Balczerski B, Bump P, Nichols JT, Crump JG. 2016. Competition between Jagged-Notch and Endothelin1 signaling selectively restricts cartilage formation in the zebrafish upper face. PLoS Genet. 12:e1005967. doi:10.1371/journal.pgen.1005967

Bayram B, Uckan S, Cetinsahin A, Arman Ozcirpici A, Ozdemir H, Yazici C. 2010. Repositioning of the masseter muscle and its effect on skeletal growth. Oral Surg. Med. Pathol. Radiol.

Endodontol. 109:e1-e5. doi:10.1016/j.tripleo.2009.12.041

Bixler D, Ward R, Gale DD. 1985. Agnathia-holoprosencephaly: A developmental field complex involving face and brain. Report of 3 cases. J. Craniofac. Genet. Dev. Biol. Suppl 1:241-249.

Blom H, Märss T. 2010. The interrelationships and evolutionary history of anaspid fishes In: Elliott DK, Maisey JG, Yu X, Miao D, editors. Morphology, Phylogeny and Palaeogeography of Fossil Fishes - Honoring Meemann Chang. Munich: Verlag Dr. Fredrich Pfeil.

Blom H, Märss T, Miller CG. 2001. Silurian and earliest Devonian birkeniid anaspids from the Northern Hemisphere. Eart. Envir. Sci. Trans. R. Soc. Edinbur. 92:263-323. doi:10.1017/S0263593300000250

Brown DM, Marsh JL. 1990. Agnathia and associated malformations: A case report. Clef. Palat. J. 27:415-418. doi:10.1597/1545-1569_1990_027_0415_aaamac_2.3.co_2 
Miyashita et al. - Functionally jawless zebrafish 21

607 Cairns DM, Sato ME, Lee PG, Lassar AB, Zeng L. 2008. A gradient of Shh establishes mutually

608 repressing somitic cell fates induced by Nkx3.2 and Pax3. Dev. Biol. 323:152-165.

609 doi:10.1016/j.ydbio.2008.08.024

610 Caron MMJ, Emans PJ, Surtel DAM, van der Kraan PM, van Rhijn LW, Welting TJM. 2015. BAPX-

611 1/NKX-3.2 acts as a chondrocyte hypertrophy molecular switch in osteoarthritis. Arthrit.

$612 \quad$ Rheumatol. 67:2944-2956. doi:10.1002/art.39293

613 Cerny R, Cattell M, Sauka-Spengler T, Bronner-Fraser M, Yu F, Medeiros DM. 2010. Evidence for the 614 prepattern/cooption model of vertebrate jaw evolution. Proc. Nat. Acad. Sci. 107:17262-17267. 615 doi:10.1073/pnas.1009304107

616 Chidzonga MM. 1999. Temporomandibular joint ankylosis: Review of thirty-two cases. Brit. J. Oral 617 Maxillofac. Surg. 37:123-126. doi:10.1054/bjom.1997.0089

618 Cubbage CC, Mabee PM. 1996. Development of the cranium and paired fins in the zebrafish Danio 619 rerio (Ostariophysi, Cyprinidae). J. Morphol. 229:121-160. doi:10.1002/(SICI)10974687(199608)229:2<121::AID-JMOR1>3.0.CO;2-4

621 Depew MJ, Compagnucci C. 2008. Tweaking the hinge and caps: Testing a model of the organization of jaws. J. Exp. Zool. 310B:315-335. doi:10.1002/jez.b.21205

Donoghue PCJ, Forey PL, Aldridge RJ. 2000. Conodont affinity and chordate phylogeny. Biol. Rev. 75:191-251.

Depew MJ, Simpson CA. 2006. 21st Century neontology and the comparative development of the vertebrate skull. Dev. Dyn. 235:1256-1291. doi:10.1002/dvdy.20796

Depew MJ, Simpson CA, Morasso M, Rubenstein JLR. 2005. Reassessing the Dlx code: The genetic regulation of branchial arch skeletal pattern and development. J. Anat. 207:501-561. doi:10.1111/j.1469-7580.2005.00487.x

Edgell TC, Neufeld CJ. 2008. Experimental evidence for latent developmental plasticity: Intertidal whelks respond to a native but not an introduced predator. Biol. Let. 4:385-387. doi:10.1098/rsbl.2008.0204 insertion and large-scale assessment of single-guide RNAs. PLoS One 9:e98186. 
Miyashita et al. - Functionally jawless zebrafish 22

Galis F. 1993. Interactions between the pharyngeal jaw apparatus, feeding behaviour, and ontogeny in the cichlid fish, Haplochromis piceatus: A study of morphological constraints in evolutionary ecology. J. Exp. Zool. 267:137-154. doi:10.1002/jez.1402670207

Gekas J, Li B, Kamnasaran D. 2010. Current perspectives on the etiology of agnathia-otocephaly. European J. Med. Genet. 53:358-366. doi:10.1016/j.ejmg.2010.09.002

Gillis JA, Modrell MS, Baker CVH. 2013. Developmental evidence for serial homology of the vertebrate jaw and gill arch skeleton. Nat. Commun. 4:1436. doi:10.1038/ncomms2429

Gomes FEF, Moraes RB, Luz JG de C. 2012. Effects of temporal muscle detachment and coronoidotomy on facial growth in young rats. Braz. Oral Res. 26:348-354. doi:10.1590/S1806-83242012000400011

Greenwood PH. 1965. Environmental effects on the phar-yngeal mill of a cichlid fish,Astatoreochromis alluaudi, and their taxonomic implications. Proc. Linn. Soc. Lond. 176:1-10.

Hall BK. 2015. Bones and Cartilage: Developmental and Evolutionary Skeletal Biology. 2nd edition. London: Academic Press.

Hawkins MB, Henke K, Harris MP. 2018. Latent developmental potential to form limb-like skeletal structures in zebrafish. bioRxiv 450619. doi:10.1101/450619

Hecksher-Sørensen J, Watson RP, Lettice LA, Serup P, Eley L, Angelis CD, Ahlgren U, Hill RE. 2004. The splanchnic mesodermal plate directs spleen and pancreatic laterality, and is regulated by Bapx1/Nkx3.2. Development 131:4665-4675. doi:10.1242/dev.01364

Hellemans J, Simon M, Dheedene A, Alanay Y, Mihci E, Rifai L, Sefiani A, van Bever Y, Meradji M, Superti-Furga A, Mortier G. 2009. Homozygous inactivating mutations in the NKX3-2 gene result in spondylo-megaepiphyseal-metaphyseal dysplasia. Am. J. Hum. Genet. 85:916-922. doi:10.1016/j.ajhg.2009.11.005

Herbrand H, Pabst O, Hill R, Arnold H-H. 2002. Transcription factors Nkx3.1 and Nkx3.2 (Bapx1) play an overlapping role in sclerotomal development of the mouse. Mec. Dev. 117:217-224. doi:10.1016/S0925-4773(02)00207-1

Hernandez LP. 2000. Intraspecific scaling of feeding mechanics in an ontogenetic series of zebrafish, Danio rerio. J. Exp. Biol. 203:3033-3043.

Hernandez LP, Bird NC, Staab KL. 2007. Using zebrafish to investigate cypriniform evolutionary novelties: Functional development and evolutionary diversification of the kinethmoid. J. Exp. Zool. 308B:625-641. doi:10.1002/jez.b.21166

Horowitz SL, Shapiro HH. 1955. Modification of skull and jaw architecture following removal of the masseter muscle in the rat. Am. J. Phys. Anthropol. 13:301-308. doi:10.1002/ajpa.1330130208 
Miyashita et al. - Functionally jawless zebrafish 23

673

674

675

676

677

678

679

680

681

682

683

684

685

686

687

688

689

690

691

692

693

694

695

696

697

698

699

700

701

702

703

704

705

Howland HC, Merola S, Basarab JR. 2004. The allometry and scaling of the size of vertebrate eyes.

Vis. Res. 44:2043-2065. doi:10.1016/j.visres.2004.03.023

$\mathrm{Hu}$ Y, Albertson RC. 2017. Baby fish working out: An epigenetic source of adaptive variation in the cichlid jaw. Proc R Soc B 284:20171018. doi:10.1098/rspb.2017.1018

Janvier P. 2007. Homologies and evolutionary transitions in early vertebrate history In: Anderson JS, Sues H-D, editors. Major Transitions in Vertebrate Evolution. Bloomington: Indiana University Press. pp. 57-121.

Janvier P. 1996. Early Vertebrates, Oxford Monographs on Geology and Geophysics. Oxford: Clarendon Press.

Kaji T, Palmer AR. 2017. How reversible is development? Contrast between developmentally plastic gain and loss of segments in barnacle feeding legs. Evolution 71:756-765. doi:10.1111/evo.13152

Kawato Y, Hirao M, Ebina K, Shi K, Hashimoto J, Honjo Y, Yoshikawa H, Myoui A. 2012. Nkx3.2 promotes primary chondrogenic differentiation by upregulating Col2a1 transcription. PLoS One 7:e34703. doi:10.1371/journal.pone.0034703

Keating JN, Donoghue PCJ. 2016. Histology and affinity of anaspids, and the early evolution of the vertebrate dermal skeleton. Proc. R. Soc. B 283:20152917. doi:10.1098/rspb.2015.2917

Kiaer J. 1924. The Downtonian fauna of Norway. I. Anaspida with a geological introduction. Skrifter 6:1-139.

Kimmel CB, Ballard WW, Kimmel SR, Ullmann B, Schilling TF. 1995. Stages of embryonic development of the zebrafish. Dev. Dyn. 203:253-310. doi:10.1002/aja.1002030302

Klingenberg CP. 2011. MorphoJ: An integrated software package for geometric morphometrics. Mol. Ecol. Res. 11:353-357. doi:10.1111/j.1755-0998.2010.02924.x

Kuratani S. 2012. Evolution of the vertebrate jaw from developmental perspectives. Evol. Dev. 14:7692. doi:10.1111/j.1525-142X.2011.00523.x

Labun K, Montague TG, Gagnon JA, Thyme SB, Valen E. 2016. CHOPCHOP v2: A web tool for the next generation of CRISPR genome engineering. Nuc. Acids Res 44:W272-W276. doi:10.1093/nar/gkw398

Lauder GV. 1980. Evolution of the feeding mechanism in primitive actionopterygian fishes: A functional anatomical analysis of Polypterus, Lepisosteus, and Amia. J. Morphol. 163:283-317. doi:10.1002/jmor.1051630305

Lauder GV. 1979. Feeding mechanics in primitive teleosts and in the halecomorph fish Amia calva. J. Zool. 187:543-578. doi:10.1111/j.1469-7998.1979.tb03386.x 
Miyashita et al. - Functionally jawless zebrafish 24

706 Lengner CJ, Hassan MQ, Serra RW, Lepper C, Wijnen AJ van, Stein JL, Lian JB, Stein GS. 2005.

707 Nkx3.2-mediated repression of Runx2 promotes chondrogenic differentiation. J. Biol. Chem.

708 280:15872-15879. doi:10.1074/jbc.M411144200

709 Lettice L, Hecksher-Sørensen J, Hill R. 2001. The role of Bapx1 (Nkx3.2) in the development and

710 evolution of the axial skeleton. J. Anat. 199:181-187. doi:10.1046/j.1469-

$711 \quad 7580.2001 .19910181 . x$

712 Liem KF, Osse JWM. 1975. Biological versatility, evolution, and food resource exploitation in African

713 cichlid fishes. Integr. Comp. Biol. 15:427-454. doi:10.1093/icb/15.2.427

714 Lifshitz J. 1976. Comparative anatomic study of mandibular growth in rats after bilateral resections of

715 superficial masseter, posterior temporal, and anterior digastric muscles. J. Dent. Res. 55:854-

716 858. doi:10.1177/00220345760550052301

717 Lukas P, Olsson L. 2018a. Bapx1 is required for jaw joint development in amphibians. Evol. Dev.

$718 \quad$ 20:192-206. doi:10.1111/ede.12267

719 Lukas P, Olsson L. 2018b. Bapx1 upregulation is associated with ectopic mandibular cartilage

720 development in amphibians. Zool. Let. 4:16. doi:10.1186/s40851-018-0101-3

721 Manganello-Souza LC, Mariani PB. 2003. Temporomandibular joint ankylosis: Report of 14 cases.

722 International J. Oral Maxillofac. Surg. 32:24-29. doi:10.1054/ijom.2002.0308

723 Märss T, Turner S, Karatajūtè-Talimaa V. 2007. Handbook of Paleoichthyology / “Agnatha” II.

724 Thelodonti. München: Verlag Dr. Friedrich Pfeil.

725 Medeiros DM, Crump JG. 2012. New perspectives on pharyngeal dorsoventral patterning in

726 development and evolution of the vertebrate jaw. Dev. Biol. 371:121-135.

727 doi:10.1016/j.ydbio.2012.08.026

728 Meyer A. 1987. Phenotypic plasticity and heterochrony in Cichlasoma managuense (Pisces, Cichlidae)

729 and their implications for speciation in cichlid fishes. Evolution 41:1357-1369.

730 doi:10.1111/j.1558-5646.1987.tb02473.x

731 Miller CT, Yelon D, Stainier DYR, Kimmel CB. 2003. Two endothelin 1 effectors, hand2 and bapx1,

732 pattern ventral pharyngeal cartilage and the jaw joint. Development 130:1353-1365.

733 doi:10.1242/dev.00339

734 Miyashita T. 2016. Fishing for jaws in early vertebrate evolution: A novel hypothesis of mandibular

735 confinement. Biol. Rev. 91:611-657. doi:10.1111/brv.12187

736 Miyashita T. 2012. Comparative Analysis of the Anatomy of the Myxinoidea and the Ancestry of Early

737 Vertebrate Lineages (Unpublished M.Sc. thesis). Edmonton: University of Alberta. 
Miyashita et al. - Functionally jawless zebrafish 25

738

739

740

741

742

743

744

745

746

747

748

749

750

751

752

753

754

755

756

757

758

759

760

761

762

763

764

765

766

767

768

769

770

Miyashita T, Coates MI, Farrar R, Larson P, Manning PL, Wogelius RA, Edwards NP, Anné J, Bergmann U, Palmer AR, Currie PJ. 2019. Hagfish from the Cretaceous Tethys Sea and a reconciliation of the morphological-molecular conflict in early vertebrate phylogeny. Proc. Nat. Acad. Sci. 116:2146-2151. doi:10.1073/pnas.1814794116

Miyazaki M, Yonemitsu I, Takei M, Kure-Hattori I, Ono T. 2016. The imbalance of masticatory muscle activity affects the asymmetric growth of condylar cartilage and subchondral bone in rats. Arc. Oral Biol. 63:22-31. doi:10.1016/j.archoralbio.2015.11.020

Montague TG, Cruz JM, Gagnon JA, Church GM, Valen E. 2014. CHOPCHOP: A CRISPR/Cas9 and TALEN web tool for genome editing. Nuc. Acids Res. 42:W401-W407. doi:10.1093/nar/gku410

Murtaugh LC, Zeng L, Chyung JH, Lassar AB. 2001. The chick transcriptional repressor Nkx3.2 acts downstream of Shh to promote BMP-dependent axial chondrogenesis. Dev. Cell 1:411-422. doi:10.1016/S1534-5807(01)00039-9

Neufeld CJ, Palmer AR. 2008. Precisely proportioned: Intertidal barnacles alter penis form to suit coastal wave action. Proc. R. Soc. B 275:1081-1087. doi:10.1098/rspb.2007.1760

Palmer AR. 2012. Developmental plasticity and the origin of novel forms: Unveiling cryptic genetic variation via "use and disuse." J. Exp. Zool. Part 318B:466-479. doi:10.1002/jez.b.21447

Provot S, Kempf H, Murtaugh LC, Chung U, Kim D-W, Chyung J, Kronenberg HM, Lassar AB. 2006. Nkx3.2/Bapx1 acts as a negative regulator of chondrocyte maturation. Development 133:651662. doi:10.1242/dev.02258

Rodrigues L, Traina AA, Nakamai LF, Luz JG de C. 2009. Effects of the unilateral removal and dissection of the masseter muscle on the facial growth of young rats. Braz. Oral Res. 23:89-95. doi:10.1590/S1806-83242009000100015

Rohlf FJ. 2018. tpsDIG. New York.

Rohlf FJ. 1999. Shape statistics: Procrustes superimpositions and tangent spaces. J. Classif. 16:197223. doi:10.1007/s003579900054

Sansom RS, Freedman K, Gabbott SE, Aldridge RJ, Purnell MA. 2010. Taphonomy and affinity of an enigmatic Silurian vertebrate, Jamoytius kerwoodi White. Palaeontology 53:1393-1409. doi:10.1111/j.1475-4983.2010.01019.x

Sarnat BG. 1970. The face and jaws after surgical experimentation with the septovomeral region in growing and adult rabbits. Acta Oto-Laryngol. 69:1-30. doi:10.3109/00016487009131762

Sarnat BG, Muchnic H. 1971. Facial skeletal changes after mandibular condylectomy in the adult monkey. J. Anat. 108:323-338. 
Miyashita et al. - Functionally jawless zebrafish 26

771 Schiffer C, Tariverdian G, Schiesser M, Thomas MC, Sergi C. 2002. Agnathia-otocephaly complex:

Report of three cases with involvement of two different Carnegie stages. Am. J. Med. Genet. 112:203-208. doi:10.1002/ajmg.10672

Schilling TF, Kimmel CB. 1997. Musculoskeletal patterning in the pharyngeal segments of the zebrafish embryo. Development 124:2945-2960.

Schneider A, Mijalski T, Schlange T, Dai W, Overbeek P, Arnold H-H, Brand T. 1999. The homeobox gene it NKX3.2 is a target of left-right signalling and is expressed on opposite sides in chick and mouse embryos. Curr. Biol. 9:911-S1. doi:10.1016/S0960-9822(99)80397-2

Slijper EJ. 1942a. Biologic-anatomical investigations on the bipedal gait and upright posture in mammals, with special reference to a little goat, born without forelegs. I. Proc. Konink. Ned. Akad. Wet. 45:288-295.

Slijper EJ. 1942b. Biologic-anatomical investigations on the bipedal gait and upright posture in mammals, with special reference to a little goat, born without forelegs. II. Proc. Konink. Ned. Akad. Wet. 45:407-415.

Smeeton J, Askary A, Gage Crump J. 2016. Building and maintaining joints by exquisite local control of cell fate. WIREs Dev. Biol. 6:e245. doi:10.1002/wdev.245

Smith KK, Schneider RA. 1998. Have gene knockouts caused evolutionary reversals in the mammalian first arch? BioEssays 20:245-255. doi:10.1002/(SICI)1521-1878(199803)20:3<245::AIDBIES8>3.0.CO;2-Q

Smith LD, Palmer AR. 1994. Effects of manipulated diet on size and performance of brachyuran crab claws. Science 264:710-712. doi:10.1126/science.264.5159.710

Standen EM, Du TY, Larsson HCE. 2014. Developmental plasticity and the origin of tetrapods. Nature 513:54-58. doi:10.1038/nature 13708

Stewart TA, Albertson RC. 2010. Evolution of a unique predatory feeding apparatus: Functional anatomy, development and a genetic locus for jaw laterality in Lake Tanganyika scale-eating cichlids. BMC Biol. 8:8. doi:10.1186/1741-7007-8-8

Toledo LG, Cavalcanti SCXB, Corrêa L, Luz JGC. 2014. Effects of injury or removal of the articular disc on maxillomandibular growth in young rats. J. Oral Maxillofac. Surg. 72:2140-2147. doi:10.1016/j.joms.2014.06.445

Tucker AS, Watson RP, Lettice LA, Yamada G, Hill RE. 2004. Bapx1 regulates patterning in the middle ear: Altered regulatory role in the transition from the proximal jaw during vertebrate evolution. Development 131:1235-1245. doi:10.1242/dev.01017 
Miyashita et al. - Functionally jawless zebrafish 27

803

804

805

806

807

808

809

810

811

812

813

814

815

816

817

818

819

820

821

822

823

824

825

826

827

828

829

830

831

832

833

834

West-Eberhard MJ. 2005a. Developmental plasticity and the origin of species differences. Proc. Nat. Acad. Sci. 102:6543-6549. doi:10.1073/pnas.0501844102

West-Eberhard MJ. 2005b. Phenotypic accommodation: Adaptive innovation due to developmental plasticity. J. Exp. Zool. 304B:610-618. doi:10.1002/jez.b.21071

West-Eberhard MJ. 2003. Developmental Plasticity and Evolution, 1 edition. ed. Oxford; New York: Oxford University Press.

Westneat MW. 2004. Evolution of levers and linkages in the feeding mechanisms of fishes. Integr Comp Biol 44:378-389. doi:10.1093/icb/44.5.378

Westneat MW. 2005. Skull biomechanics and suction feeding in fishes. Fish Physiology, Fish Biomechanics. Academic Press. pp. 29-75. doi:10.1016/S1546-5098(05)23002-9

Wilson J, Tucker AS. 2004. Fgf and Bmp signals repress the expression of Bapx1 in the mandibular mesenchyme and control the position of the developing jaw joint. Dev. Biol. 266:138-150. doi:10.1016/j.ydbio.2003.10.012

Wilson MVH, Caldwell MW. 1998. The Furcacaudiformes: A new order of jawless vertebrates with thelodont scales, based on articulated Silurian and Devonian fossils from northern Canada. $J$. Vert. Paleontol. 18:10-29. doi:10.1080/02724634.1998.10011031

Wilson MVH, Caldwell MW. 1993. New Silurian and Devonian fork-tailed "thelodonts" are jawless vertebrates with stomachs and deep bodies. Nature 361:442-444. doi:10.1038/361442a0

Wimberger PH. 1992. Plasticity of fish body shape. The effects of diet, development, family and age in two species of Geophagus (Pisces: Cichlidae). Biol. J. Linn. Soc. 45:197-218. doi:10.1111/j.1095-8312.1992.tb00640.x

Wimberger PH. 1991. Plasticity of jaw and skull morphology in the Neotropical cichlids Geophagus Brasiliensis and G. Steindachneri. Evolution 45:1545-1563. doi:10.1111/j.15585646.1991.tb02662.x

Yamashita S, Andoh M, Ueno-Kudoh H, Sato T, Miyaki S, Asahara H. 2009. Sox9 directly promotes Bapx1 gene expression to repress Runx2 in chondrocytes. Exp. Cell Res. 315:2231-2240. doi:10.1016/j.yexcr.2009.03.008

Zeng L, Kempf H, Murtaugh LC, Sato ME, Lassar AB. 2002. Shh establishes an Nkx3.2/Sox9 autoregulatory loop that is maintained by BMP signals to induce somitic chondrogenesis. Genes Dev. 16:1990-2005. doi:10.1101/gad.1008002 
bioRxiv preprint doi: https://doi org/10.1101/776351; this version posted October 18 2019. The copyright holder for this preprint (which was not certified by peer review) is the author/funder, who has granted bioRxiv a license to display the preprint in perpetuity. It is made available under aCC-BY-NC 4.0 International license.

Miyashita et al. - Functionally jawless zebrafish 28

A. $n k \times 3.2$ mutations

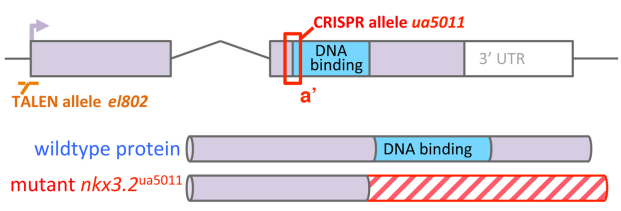

A'. $n k \times 3.2$ mutant allele ua5011

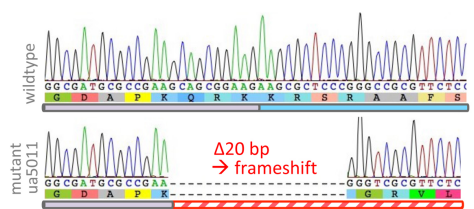

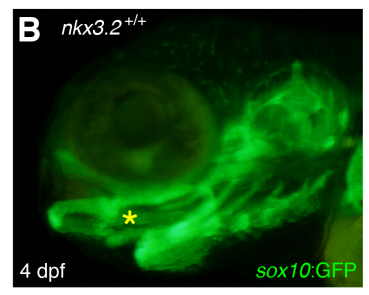

$\mathbf{E} n k \times 3.2^{+/+}$

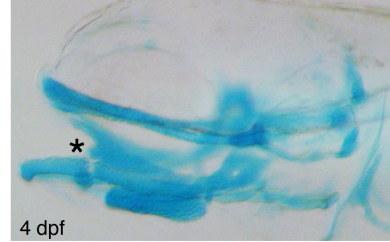

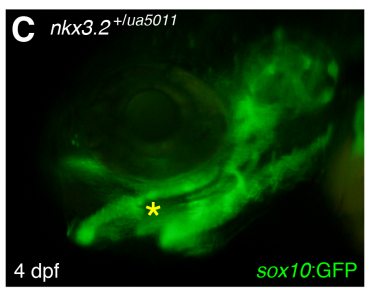

F $n k \times 3.2^{+/ 4 a 5011}$

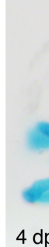

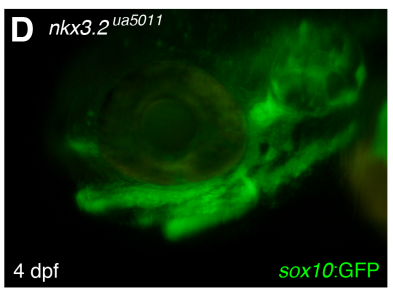

G $n k \times 3.2^{\text {ua5011 }}$

$4 \mathrm{dpf}$

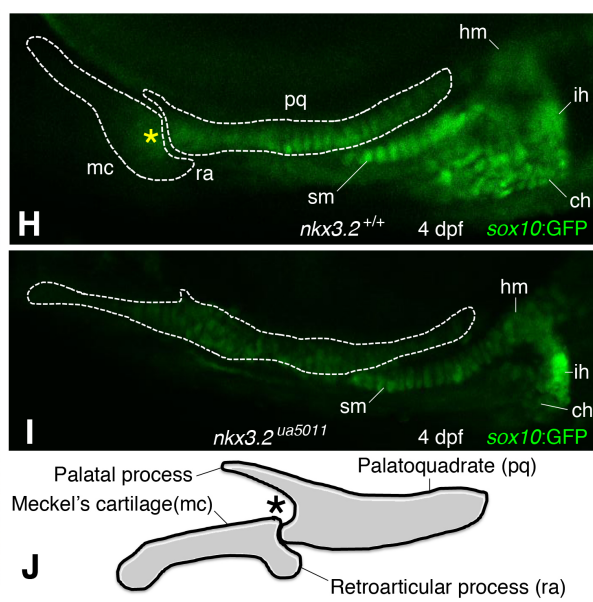

Fig. 1. Null alleles of $n k x 3.2$ in zebrafish result in the jaw joint ankylosis.

(A) Mutations engineered with CRISPR/Cas9 or TALEN in the zebrafish gene $n k x 3.2$ that encodes the homeobox transcription factor protein Nkx3.2 (a.k.a. Bapx1). Top: The gene $n k x 3.2$ contains two exons (purple), the second of which encodes the homeobox domain (DNA binding domain, blue). The diagram is approximately to scale (exon $1=310 \mathrm{bp}$ ), except the 3' untranslated region (3'UTR). Allele $n k x 3.2^{e l 802}$ was generated with TALEN technology that deleted $20 \mathrm{bp}$ from the start of the gene (orange dashed line), eliminating the start codon. Allele $n k x 3.2^{\text {ua5011 }}$ was engineered with CRISPR/Cas9 to generate a 20 bp deletion (red box) and frameshift that is predicted to eliminate the homeodomain. Bottom: Schematic of predicted protein following CRISPR mutagenesis. In the allele $n k x 3.2^{\text {ua5011 }}$, the frameshift (20 bp deletion) is predicted to disrupt the translation and abrogate production of the critical homeobox domain. This is predicted to produce random amino acids (red hatching). (A') Sequencing results from allele $n k x 3 \cdot 2^{\text {ua5011 }}$ (lower) compared to a wildtype zebrafish (upper).

At 4 dpf, the chondrocrania are compared by sox 10:eGFP expression in chondrocytes (B-D, $\mathbf{H}$, chondrocranial morphology of wildtypes (AB background; sox 10:eGFP) at $4 \mathrm{dpf}$ in left lateral view, in sox 10:eGFP expression within chondrocytes (B) and alcian blue staining of cartilages (E). (C, F) The chondrocranial morphology of $n k x 3.2$ heterozygous mutants $\left(n k x 3.2^{+/ u a 5011} ;\right.$ sox 10:eGFP) at 4 dpf in 
Miyashita et al. - Functionally jawless zebrafish 29

856 cartilages $(\mathrm{F}) .(\mathbf{D}, \mathbf{G})$ The chondrocranial morphology of $n k x 3.2$ homozygous mutants $\left(n k x 3.2^{\text {ua5011 }}\right.$;

857 sox 10:eGFP) at $4 \mathrm{dpf}$ in left lateral view, in sox 10:eGFP expression within chondrocytes (D) and alcian

858 blue staining of cartilages $(\mathrm{G})$. (H, I) Comparison of jaw morphology between age-matched wildtype

859 (AB background; sox 10:eGFP) (H) and $n k x 3.2$ homozygous mutants $\left(n k x 3.2^{\text {ua5011 }}\right.$; sox 10:eGFP) (I) at 4

$860 \mathrm{dpf}$ in left lateral view, using sox 10:eGFP expression within chondrocytes. White broken lines

861 delineate the mandibular cartilages. (J) Schematic drawing of the mandibular cartilages in zebrafish at

$8624 \mathrm{dpf}$ in left lateral view, showing wildtype morphology (see panel E).

863 Abbreviations: asterisk (*), jaw joint; aa, anguloarticular; ar, articular; bh, basihyal; ch,

864 ceratohyal; d, dentary; dpf, days post fertilization; hm, hyomandibula; ih, interhyal; j, jugal; ke,

865 kinethmoid; lp, lower lip; mc, Meckel's cartilage; m, maxilla; n, nostril or aperture of nasohypophyseal

866 system; o, operculum; pm, premaxilla; po, preopercular; pq, palatoquadrate; q, quadrate; ra,

867 retroarticular process; sm, symplectic; up, upper lip. 
Miyashita et al. - Functionally jawless zebrafish 30

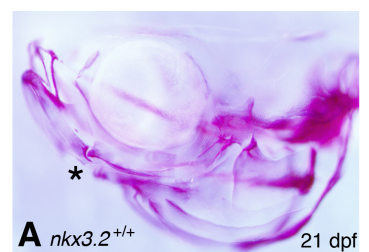

A $n k \times 3.2^{+/+}$

$\mathbf{F}$
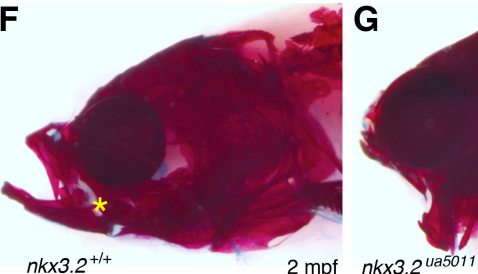

Wildtype (nkx3.2+/+ $2 \mathrm{mpf})$
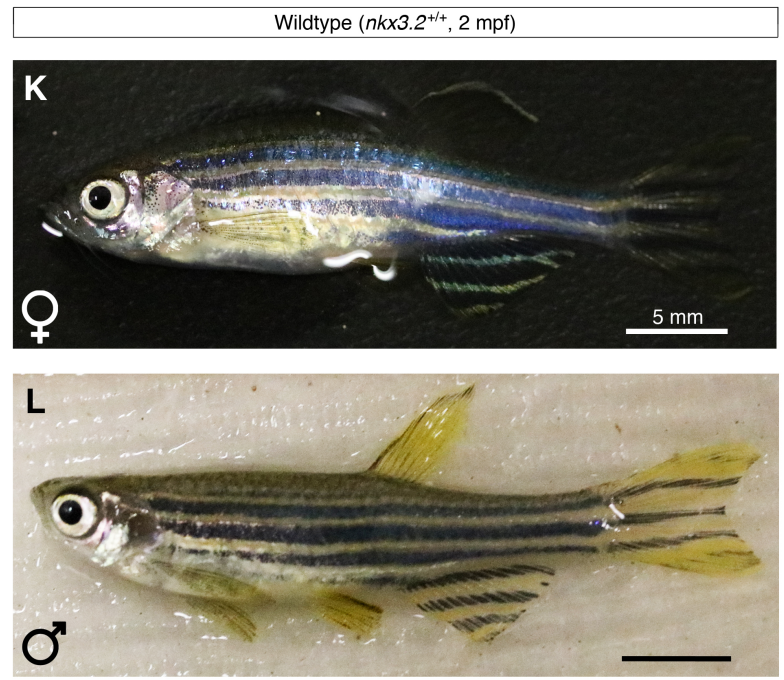
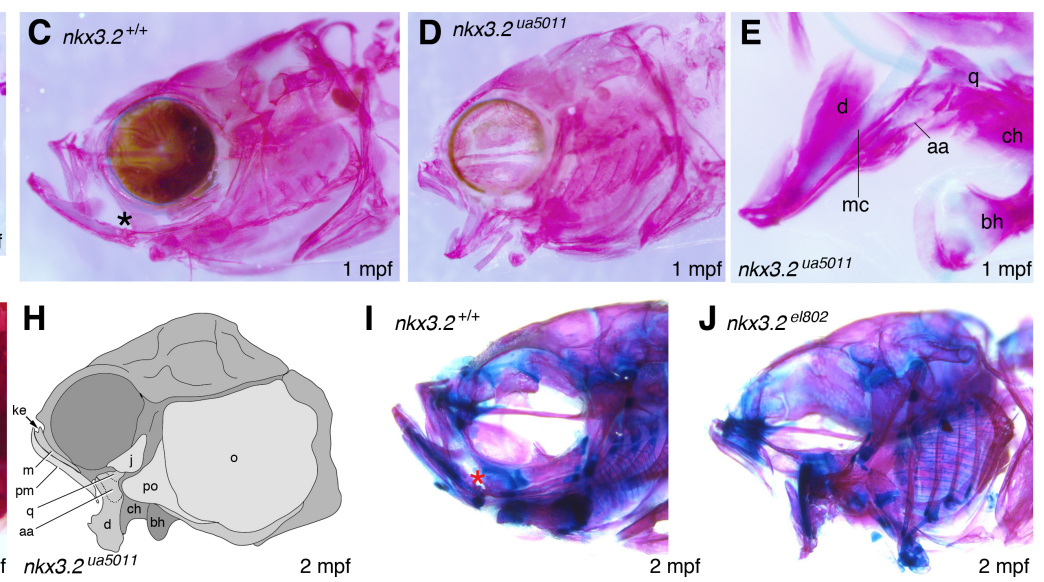
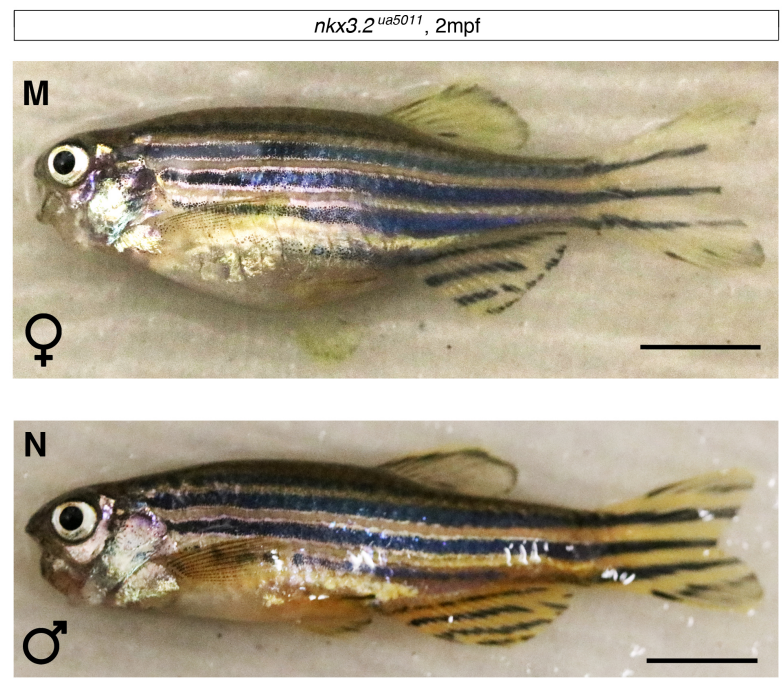

Fig. 2. Ontogeny of $n k x 3.2^{-/}$zebrafish documents drastic remodeling of the skull.

(A, B) Comparison of the skull morphology between age-matched wildtype (AB strain) (A) and $n k x 3.2$ homozygous mutant $\left(n k x 3.2^{\text {uas011 }}\right)$

(B) at $21 \mathrm{dpf}$ in right lateral view (inverted for consistency with other panels), using alcian blue and alizarin red staining. (C, D) Comparison of skull morphology between age-matched wildtype (AB) (C) and $n k x 3.2$ homozygous mutant $\left(n k x 3.2^{\text {ua5011 }}\right)$ (D) at $1 \mathrm{mpf}$ in left lateral view, using alcian blue and alizarin red staining. (E) Detailed morphology of jaw skeleton in $n k x 3.2$ homozygous mutant $\left(n k x 3.2^{u a 5011}\right)$ at $1 \mathrm{mpf}$ in right lateral view (inverted for consistency with other panels), using alcian blue and alizarin red staining.

$(\mathbf{F}, \mathbf{G})$ Comparison of skull morphology between age-matched wildtype (AB) (F) and $n k x 3.2$ homozygous mutant $\left(n k x 3.2^{\text {uas011 }}\right)(\mathrm{G})$ at $2 \mathrm{mpf}$ in left lateral view, using alcian blue and alizarin red staining. (H) Interpretive drawing of the specimen in panel $\mathrm{g}$. homozygous mutant $\left(n k \times 3.2^{e l 802}\right)(\mathrm{J})$ at $2 \mathrm{mpf}$ in left lateral view, using alcian blue and alizarin red staining. This second independent null allele of $n k x 3.2$ confirms the phenotypes reported herein. 
bioRxiv preprint doi: https://doi.org/10.1101/776351; this version posted October 18,2019 . The copyright holder for this preprint (which was not certified by peer review) is the author/funder, who has granted bioRxiv a license to display the preprint in perpetuity. It is made available under aCC-BY-NC 4.0 International license.

Miyashita et al. - Functionally jawless zebrafish 31

884

(K-N) Comparison of overall morphology at $2 \mathrm{mpf}$ among age-matched wildtype (AB)

885 female $(\mathrm{K})$ and male $(\mathrm{L})$ and $n k x 3.2$ homozygous mutant $\left(n k x 3.2^{\text {el802}}\right)$ female $(\mathrm{M})$ and male $(\mathrm{N})$ in left

886 lateral view. Scale bars $=5 \mathrm{~mm}$. Abbreviations follow Fig. 1.

887

888 
bioRxiv preprint doi: https://doi.org/10.1101/776351; this version posted October 18,2019 . The copyright holder for this preprint (which was not certified by peer review) is the author/funder, who has granted bioRxiv a license to display the preprint in perpetuity. It is made available under aCC-BY-NC 4.0 International license.

Miyashita et al. - Functionally jawless zebrafish 32
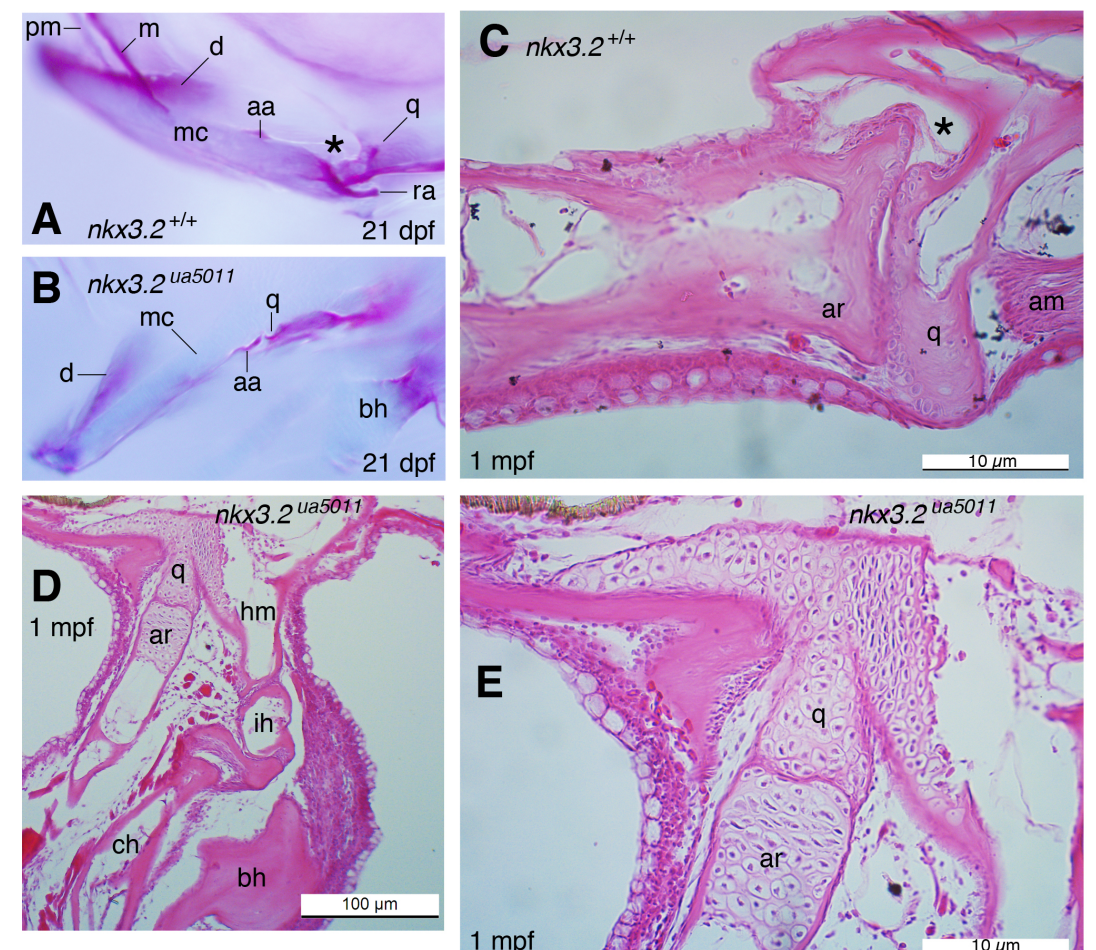

889

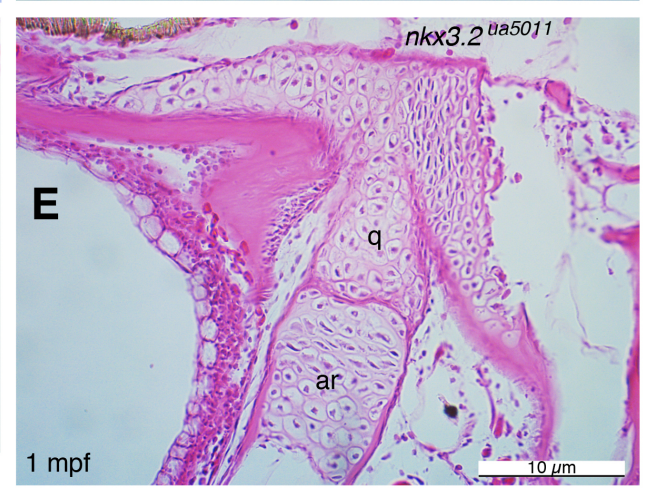

890 Fig. 3. Detailed morphology of jaw joint in wildtype, or the joint-less interface between the upper 891 and lower jaws in $n k x 3.2^{-/-}$mutants.

(A, B) Detailed morphology of junction between upper and lower jaws in age-matched wildtype (A) and $n k x 3.2$ homozygous mutant $\left(n k x 3.2^{\text {ua5011 }}\right)$ (B) at $21 \mathrm{dpf}$ in left lateral view, using alcian blue 894 and alizarin red staining. (C, D) Sagittal section of junction between upper and lower jaws in age895 matched wildtype (AB) (C) and $n k x 3.2$ homozygous mutant $\left(n k x 3.2^{\text {ua5011 }}\right)$ (D) at $1 \mathrm{mpf}$, stained with eosin and hematoxylin. (E) Detailed view of section in panel D. 
A. Ontogeny of gape angles in wildtype and mutant zebrafish

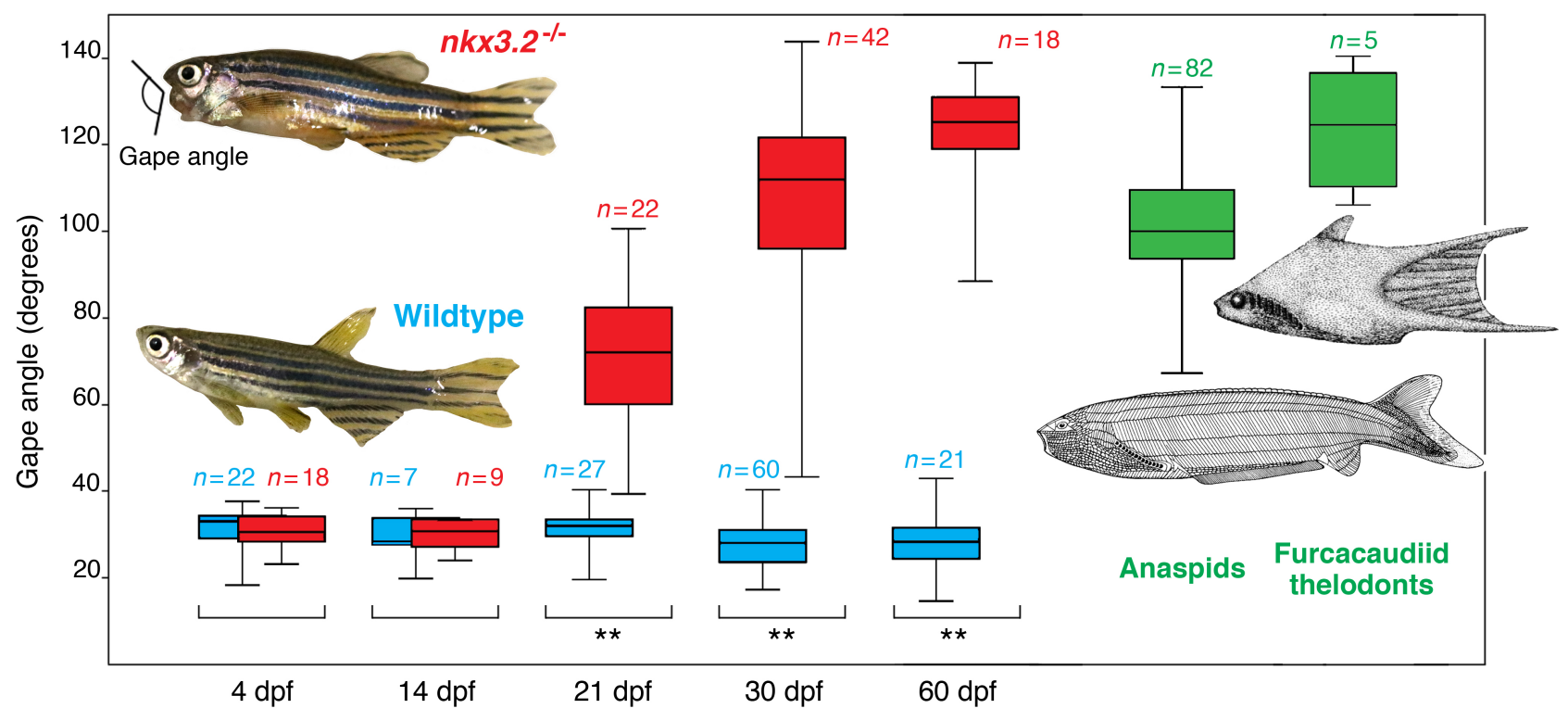

B. Overall skull growth in wildtype and mutant zebrafish

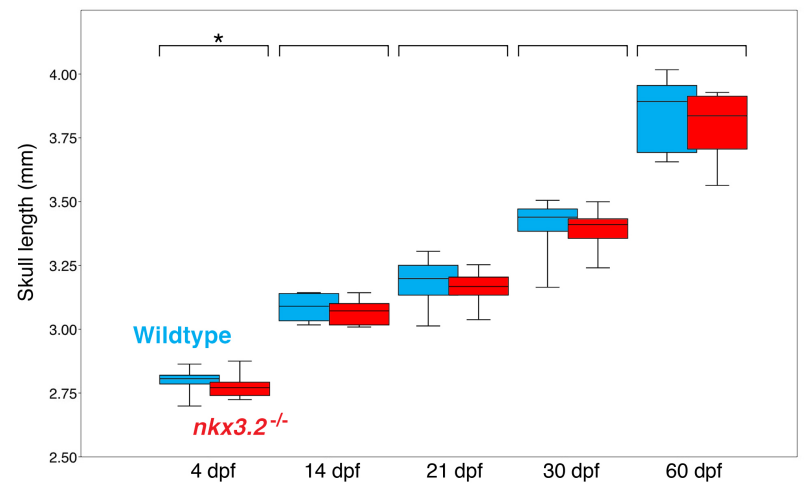

C. Ontogeny of lower jaws in wildtype and mutant zebrafish

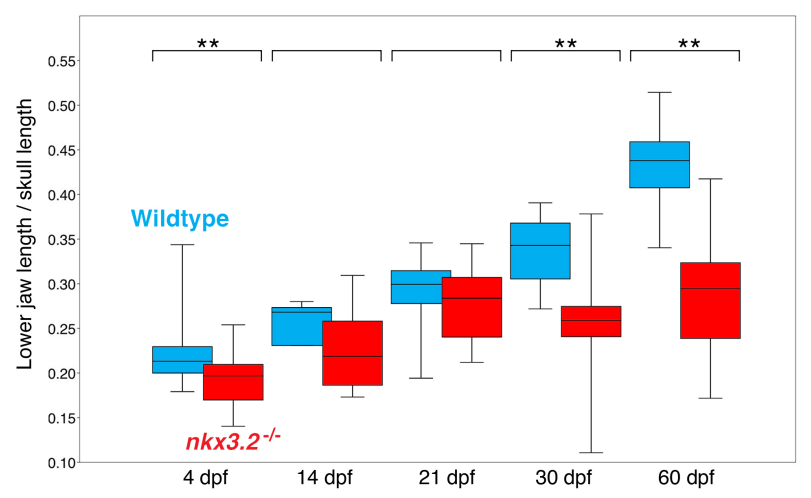

Fig. 4. Growth of $n k x 3.2^{-/-}$mutants in linear and proportional traits.

(A) A marked departure from normal morphology (wildtype = blue) occurs in lower jaw orientations of $n k x 3.2^{-/-}$zebrafish (= red) past $14 \mathrm{dpf}$, coinciding in timing with metamorphosis (onset of intramembranous ossification in the skulls and active feeding). Fixed open gapes in the mutants at 1 to $2 \mathrm{mpf}$ are comparable to those of Paleozoic agnathan lineages, birkeniiform anaspids and furcacaudiid thelodonts (green). The orientations were measured here as gape, an angle between upper and lower lips at natural, resting position.

(B) Wildtype and $n k x 3.2^{-/-}$zebrafish do not differ significantly from each other in absolute

908 sizes, except at $4 \mathrm{dpf}$. Here, skull length is selected to illustrate this general observation. (C)

909 Proportional changes appear to follow shape changes in skeletal remodeling. The box plot shows

910 phenotypic separation in relative lower jaw length between wildtype and $n k x 3.2^{-/-}$zebrafish at 1 and 2

911 mpf, even though a significant difference developed in lower jaw orientation by $21 \mathrm{dpf}$. 
bioRxiv preprint doi: https://doi.org/10.1101/776351; this version posted October 18,2019 . The copyright holder for this preprint (which was not certified by peer review) is the author/funder, who has granted bioRxiv a license to display the preprint in perpetuity. It is made available under aCC-BY-NC 4.0 International license.

Miyashita et al. - Functionally jawless zebrafish 34

$912 \quad$ Values are plotted as boxes of first and third quartile, with middle line displaying mean, and

913 whiskers communicating maximum and minimum values ( $n=$ sample size, same across A-C). Asterisk

914 indicates level of statistically significant difference in means $(t$-test $)$ : $^{*}, P<0.05 ; * *, P<0.01$.

915 Photographs of zebrafish are male representative specimens at $60 \mathrm{dpf}$ (Fig. 2L, N). Drawings are:

916 Pharyngolepis oblonga as a general representative of anaspids (after Blom et al., 2001; Kiaer, 1924);

917 and Furcacauda fredholmae as a general representative of furcacaudiid thelodonts (after Wilson and

918 Caldwell, 1993). See Data Supplement 2 for all original measurements.

919

920 
Miyashita et al. - Functionally jawless zebrafish 35

A. Wildtype
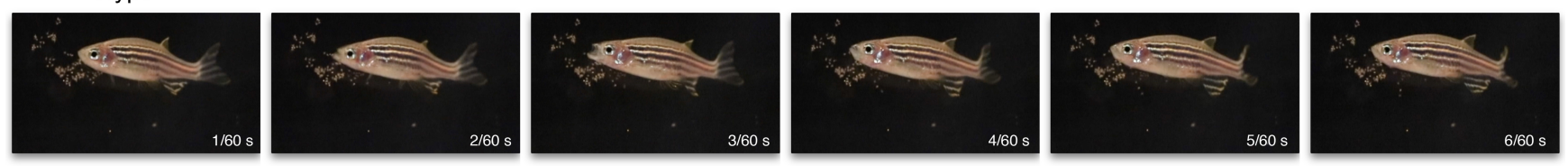

B. $n k x 3.2^{-1-}$
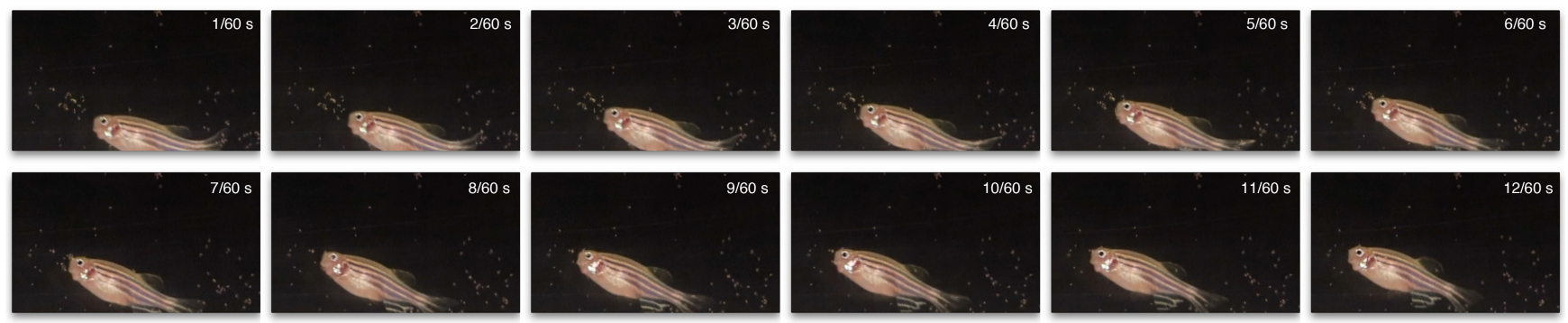

\section{Fig. 5. Functionally jawless $n k x 3.2^{-/-}$mutants perform ram feeding.}

(A) Wildtype zebrafish (6 mpf) use suction feeding, following the general principles of suction

924 feeding mechanics of actiopterygians: lower jaw depression, forward swing of premaxilla and maxilla,

925 expansion of parabranchial cavity, and recoiling motions in that order. An entire cycle takes

926 approximately $0.1 \mathrm{~s}$. (B) No suction feeding was observed in $n k x 3.2^{-/-}$zebrafish (6 mpf); instead, they

927 perform ram feeding (swim through food) with the fixed open gape. In this particular feeding episode,

928 the mutant initiated a cycle with detection of food (change in swimming orientation) and turned

929 laterally to exit that swimming trajectory in approximately $0.2 \mathrm{~s}$. Frame by frame still images from a

930 film captured at 60 frames per second. The movie is available as Supplementary Information (Movie

931 S1). 


\section{Miyashita et al. - Functionally jawless zebrafish 36}
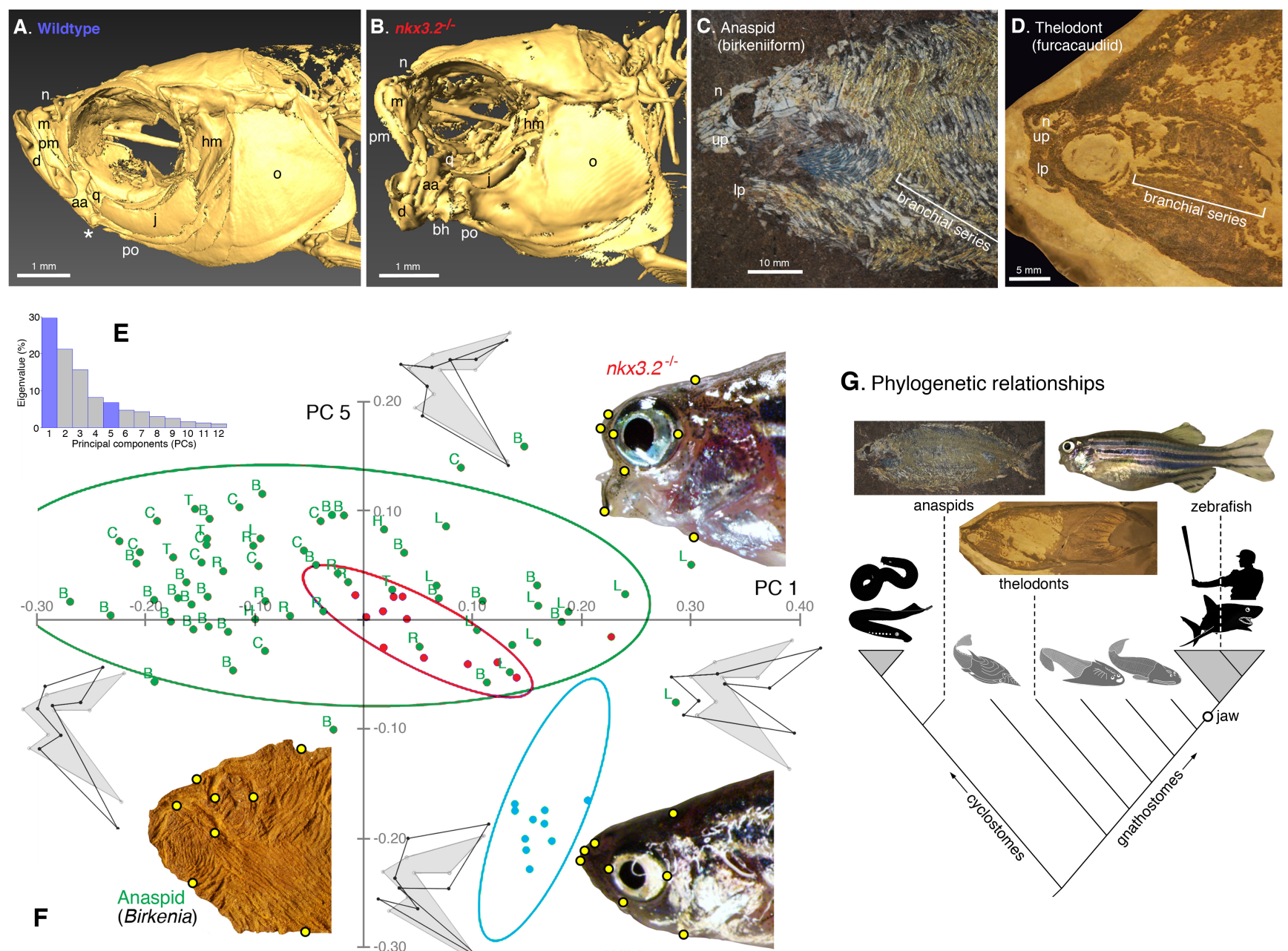

Fig. 6. Adult $n k x 3.2^{-/-}$zebrafish converge onto overall head shapes of anaspids and thelodonts.

(A, B) Skulls of adult zebrafish in left lateral view via micro-computed tomography $(\mu \mathrm{CT})$ showing wildtype and $n k x 3.2^{-/-}$null mutant zebrafish (allele ua5011; $20 \mathrm{bp}$ deletion in homeodomain).

The jaw joint is indicated by an asterisk (*) in wildtype (A) and absent in mutant (B). Adult mutants display dramatic phenotypes in the jaw, snout, lips, and orobranchial regions. See also 3D rendering in multiple angles (Movie S1). (C, D) Skulls of extinct jawless vertebrates, showing general resemblance to the skull shape of $n k x 3.2^{-/-}$zebrafish. Morphometric analysis corroborates this similarity. (C) Skull of an anaspid (birkeniid birkeniiform) from the Upper Silurian Cape Philips Formation of Cornwallis Island, Canada (Geological Survey of Canada C-26661-005) in left lateral view. (D) Skull of Sphenonectris turnerae, a thelodont (furcacaudiid furcacaudiform) from the Lower Devonian Road

944 River Formation of Northwest Territories, Canada (University of Alberta Laboratory for Vertebrate 945 Palaeontology, specimen number 42212).

$(\mathbf{E}, \mathbf{F})$ Landmark-based geometric morphometric comparison of $n k x 3.2$ phenotype using the 
Miyashita et al. - Functionally jawless zebrafish 37

948 showing loading on each principal component in eigenvalue (\%). PCs 1 and 5 are highlighted in blue.

949 These two PCs were chosen for comparison between groups, as these are the two largest components

950 that set apart $n k x 3.2$ homozygous mutants and wildtype zebrafish from each other at adult stage. PCs 2-

951 4, though accounting for greater variation than PC5, primarily distinguish among anaspids, or within

952 wildtype and mutant zebrafish groups. The original dataset is available (Data Supplement 3). (F) A

953 Cartesian plot of PCs 1 and 5, comparing morphospace occupation between wildtypes (2 mpf) (blue),

$954 n k x 3.2$ homozygous mutants (2 mpf) (red), and anaspids (green), each with 90\% ellipse. End of each

955 axis is labeled with a thin-plate-spline shape at that position (dark outline) against mean shape (grey

956 silhouette). A representative specimen is shown with landmarks labeled (yellow circles) for each group

957 in left lateral view. Each data point is a unique biological replicate (a specimen). The anaspid example

958 is Birkenia elegans (National Museum of Scotland specimen number 1929.5.6 from a Silurian locality

959 of Scotland). For anaspids, each data point is labeled with taxonomic identifications: B, Birkenia

960 elegans; C, Birkeniidae indet. from the Cornwallis Island; H, Pharyngolepis oblongus; L, Lasanius

961 problematicus; R, Ryncholepis parvulus; T, Pterygolepis nitidus.

962 (G) Simplified phylogenetic tree of vertebrates to illustrate distant relationships among the taxa 963 compared in this paper. A $60 \mathrm{dpf}$ gravid female specimen is shown for $n k x 3.2^{-/-}$zebrafish (Fig. 3M).

964 Photographs of an anaspid and a thelodont are the same individuals in the respective panels showing 965 cranial morphology (D, E). Grey triangle indicates a crown group (not to scale). Dark silhouettes and 966 long branches indicate crown groups, whereas grey silhouettes and short branches represent extinct 967 lineages. 